MOVING TOWARD GENDER FLUID DISCOURSES IN EARLY CHILDHOOD SETTINGS:

ECES SHARE THEIR EXPERIENCES AND IDEAS

by

Chloe Waters, BA, University of Winnipeg, 2017

\author{
An MRP \\ presented to Ryerson University \\ in partial fulfillment of the \\ requirements for the degree of \\ Master of Arts \\ in the Program of \\ Early Childhood Studies
}

Toronto, Ontario, Canada, 2019

(C) Chloe Waters 2019 


\section{AUTHOR'S DECLARATION FOR ELECTRONIC SUBMISSION OF A MRP}

I hereby declare that I am the sole author of this MRP. This is a true copy of the MRP, including any required final revisions.

I authorize Ryerson University to lend this MRP to other institutions or individuals for the purpose of scholarly research

I further authorize Ryerson University to reproduce this MRP by photocopying or by other means, in total or in part, at the request of other institutions or individuals for the purpose of scholarly research.

I understand that my MRP may be made electronically available to the public. 


\title{
ABSTRACT \\ MOVING TOWARD GENDER FLUID DISCOURSES IN EARLY CHILDHOOD SETTINGS: ECES SHARE THEIR EXPERIENCES AND IDEAS
}

\author{
Master of Arts, 2019 \\ Chloe Waters \\ Program of Early Childhood Studies, \\ Ryerson University
}

The dominant, yet dated discourse surrounding gender has been discussed primarily using developmental theory. Over the last thirty years, scholars have been challenging this discourse, but this is often not reflected in practice. This qualitative study is informed by a phone interview and a focus group session with educators, who believe that adopting a more gender fluid perspective with children is important. Inspired by Queer theory, employing a critical paradigm and social justice framework, it investigates how a queering of current gender discourses is being incorporated into ECEC practice. By consulting educators, the research gains insight on how gender fluid discourses can be incorporated into the field of ECEC through learning how educators are already incorporating gender fluid discourses in a proactive manor with preschool age children in ECEC settings. In the findings, five main themes were identified focusing on materials, practices, parents, ECEs, and ECE education and support.

Keywords: early childhood education and care, educators, gender fluid, reconceptualizing 


\section{ACKNOWLEDGEMENTS}

First of all, thank you to my participants for sharing their time, thoughts and ideas with me, as well as their commitments to gender fluid discourses in their practice.

To Dr. Rachel Berman, thank you not only for your thoughtful edits, dedication of time, constant support, and endless reassurance throughout this project but also for your great work as Director of this program. It takes the right kind of person to make academic settings feel supportive, safe, and encouraging and you are that person. I am so grateful to have had this opportunity to learn from you as my supervisor.

To Dr. Aurelia DiSanto, thank you for your time you committed to this project but also for sharing your passion, commitment and knowledge of children's rights with me in class. I am fortunate to have had you be a part of this project, thank you for your support.

To Sophia, for making sure I felt welcome in Toronto from our very first course, for endless directions, recommendations, for always having the answers to my many questions, and most of all for your friendship throughout. You saved me throughout this process more times than I can count.

To my Dad, Mom, brother, family and friends, thank you for the love and support it took me to get me to graduate school, and to get me through this year. Thank you for the many visits and for always making it feel like home was never too far away.

And most of all, to Brady for without your support, this opportunity would have (quite literally) not been possible. I am eternally grateful for your selflessness, sacrifice, patience, love, and friendship over this past year. I could not have done it without you, I love you. Now on to our next adventure... 


\section{Privilege}

It is an important practice for all individuals to take time to consider their privilege and how it has benefitted them. It is especially important for me, as a researcher to acknowledge my privilege as part of this project, especially since it is my hope that the field of Early Childhood Education and Care (ECEC) will begin to consider their own privileges and begin to incorporate this into their practice in the hopes that this might begin to create opportunities for understanding, empathy and growth. I identify as a cisgender, heterosexual, white, settler, woman.

Being cisgender and heterosexual, both my gender and sexuality have been easily accepted, as they are considered the norm. This is not the case for individuals who fall outside of this arbitrary norm, who often face discrimination and violence. Being white I have been exempted from the many forms of violence and racism that racialized people face on a daily basis that shows itself in the policies and systems of this country, and that is pervasive in the foundation of Western society and beyond. I have had the opportunity to complete my BA in developmental studies at the University of Winnipeg and my ECE III at Red River College in Winnipeg; this education happened on the stolen lands of the Métis, Anishinabewaki and Sioux people ("Native Land", n.d.). I now have had the opportunity to complete my MA degree at Ryerson University in Toronto on the stolen lands of the Anishinabewaki, Huron-Wendat and Haudenosaunee people ("Native Land", n.d.). My education and life experiences would not have been possible without the violent forces of colonialism both past and present.

It is also important to note that Indigenous perspectives on gender and sexuality were much more fluid than what is practiced and enforced in Western society today. Indigenous perspectives on gender and sexuality have been significantly impacted by colonization, through 
violence and assimilation, Indigenous people were forced into heteronormative relationships, gender roles and norms (Hunt, 2016). Despite the forceful, pervasiveness of Western perspectives of gender and sexuality, "Indigenous people have continued to live and embody non-binary expressions of gender and sexuality and to resist assimilative strategies" (Hunt, 2016, p.9).

Although this is only a brief overview of the many privileges I experience, it is with these privileges that I hold the opportunity, platform and courage to challenge and unsettle dominant discourses in ECEC settings. 


\section{TABLE OF CONTENTS}

Author's Declaration

Abstract

Acknowledgements

Privilege

Table of Contents

List of Appendices

Chapter 1. Introduction

Purpose

Importance of Research

What is the Gap?

Research Question

Road Map

Conceptual and Theoretical Frameworks

Queer Theory

Critical Paradigm
Page ii

Page iii

Page iv

Page v

Page vii

Page $x$

Page 1

Page 4

Page 6

Page 7

Page 7

Page 7

Page 8

Page 8

Page 8

Page 10

Chapter 2. Literature Review

Page 10

Dominant Discourses in ECEC

Page 12

A Shift in Ideas

Page 15

Limitations of the Current Heteronormative Developmental Discourses

Page 20

When Alternative Theories are Considered

Page 22

Disconnect Between Theory and Practice 
Summary

Page 26

Chapter 3. Methodology

Page 27

Approach

Page 27

Researcher Positionality

Page 28

Ethical Considerations

Page 28

Recruitment

Page 30

Sample

Page 32

Setting

Page 33

Data Collection

Page 33

Approach to Data Analysis

Page 35

Chapter 4. Findings

Page 38

Phone Interview

Page 38

Indirect Influence

Page 38

Direct Influence

Page 39

Focus Group Session

Page 40

Materials that Helped Support G.F.D. in the Classroom

Page 40

Practices that Helped Support G.F.D. in the Classroom

Page 41

Practices to Help Involve Parents with Incorporating G.F.D.

Page 47

The Early Childhood Educator

Page 48

Changes to ECE Education and Support

Page 51

Chapter 5. Discussion

Page 54

Materials and Practices

Page 55

Family Involvement

Page 56 
$\begin{array}{ll}\text { Barriers to Implementation } & \text { Page } 56\end{array}$

$\begin{array}{ll}\text { The Early Childhood Educator } & \text { Page } 57\end{array}$

$\begin{array}{ll}\text { Changes to ECE Education and Support } & \text { Page } 58\end{array}$

$\begin{array}{ll}\text { Strengths and Limitations } & \text { Page 62 }\end{array}$

Validity

Page 62

Worthy Topic

Page 62

Sincerity

Page 63

Ethical

Page 63

Limitations of the Research

Page 64

Future Research

Page 65

Conclusion

Page 65

Appendices

Page 67

References

Page 92 


\section{LIST OF APPENDICES}

Appendix A - Glossary of terms

Page 67

Appendix B - REB approval

Page 69

Appendix C - Recruitment flyer

Page 70

Appendix D - Consent form A (phone interview)

Page 71

Appendix E - Consent form B (focus group)

Page 79

Appendix F - Demographic questionnaire

Page 87

Appendix G - Phone interview questions

Page 89

Appendix $\mathrm{H}$ - Focus group questions

Page 90 


\section{CHAPTER 1. INTRODUCTION}

Historically, the field of Early Childhood Education and Care (ECEC) has been standardized and justified through child development theory (Berman \& Abwai, 2019; Blaise, 2005; Nxumalo \& Keys Adair, 2019). Dating back to the early twentieth century, developmental theory is based on the literature and contexts of an earlier time frame that neglects to adequately represent the social complexities of our current world (Blaise, 2005). Reconceptualist scholars have long questioned both the use and efficiency of a strictly developmental practice in ECEC (Lubeck, 1994). This critique is especially important when dealing with complex ideas, ones that struggle to fit into such strict and limiting binaries, such as gender. Regardless, the field of ECEC seems to be "stuck in a time warp" (Blaise, 2005, p.VII) and it is critical that both the use and the reasoning behind the use of developmental theory continue to be challenged (Blaise, 2005; Pacini-Ketchabaw \& Prochner, 2013).

Given this state of affairs, the focus of much of Early Childhood Educator's (ECE) preservice education continues to be based in developmental theory. Therefore, this is the knowledge that educators are bringing to the field and into their interactions with children and families. Educators use their knowledge of child development to assess children "socially, emotionally, cognitively, and physically" (Blaise, 2005, p.2). Indeed, it is the responsibility of the educator to know and understand where each of their children are at developmentally in order to properly construct curriculum based in developmentally appropriate practice (DAP) and steeped in school readiness (Blaise, 2005; Nxumalo \& Adair, 2019).

Blaise states:

DAP privileged certain ways of being and knowing that did not recognize the diverse qualities of children and their families in a global context. In doing so, it 
had the effect of alienating the qualities of diversity that should be celebrated, and it further suggested that there was a universal state that we should all be striving for, which was based on Western ways of doing and knowing (2005, p.VII).

In her 2005 dissertation, Dr. Blaise shared how "early childhood education is coming to be known for its openness to new ideas" and how the field had been "remoulded significantly over the past decade, and alternative views and perspectives [were] beginning to have an impact on practice and pedagogies" (p.VII). This has not been my experience in the ECEC field where I worked for over nine years, and with a shift in focus of Dr. Blaise's work away from gender and sexuality in early childhood, I wonder if this statement in 2005 has held up in way that continues to represent the field of ECEC? Perhaps Dr. Blaise's positive outlook of a field that was ready for a major shift in thinking and practice failed to live up to these expectations.

In my own experience working in the childcare field, I was often surprised by the stereotypical gendered conversations and comments that I would hear taking place in the centre. These comments, that really bothered me, didn't seem to have the same effect on anyone else in the centre. I remember many moments where I had overheard my colleagues explain to a child that the thing they wanted to do, the toy they wanted to play with, or the colour they wanted to choose were 'only for girls' or 'only for boys'. I had an undeniable feeling that my purpose as an ECE was for more than meeting children's individual needs but to attend to the bigger picture, one that addresses complex issues such as social justice. I often felt such a large disconnect from my personal life when I was at work with the children. With so much focus on routine and developmental practices, potentially rich and important conversations with the children were lost. I felt my best at work when I was having open and honest conversations with children, learning and addressing aspects of their real lives, and making space for critical reflection in the 
classroom. Even though I felt strongly in my beliefs and knew that the gendered comments that were happening in the centre felt wrong, and likely having a negative impact on the children, I often found myself at a loss on how to address the situation. Through placements at other centres and discussions with other ECEs working in the field, I came to realize that this was not only a problem with one centre but seemed to be happening quite frequently across the field.

A review of the literature demonstrated that these heteronormative, gendered, stereotypical comments and conversations happening in ECEC settings are not only bothersome for me on a personal level, but can also be quite damaging for children (Breneselović \& Krnjaja, 2016; Lyttleton-Smith, 2017). Amongst other consequences, children are limited in their experiences and opportunities, learning how to place judgements about others based on heteronormative gender ideas, as well as internalizing these messages themselves (Breneselović \& Krnjaja, 2016; Lyttleton-Smith, 2017; Shutts, Kenward, Falk, Ivegran \& Fawcett, 2015).

The problem does not end there, with ECEs so easily devalued and disrespected, there is a strong want/need for educators to demonstrate the image of the "good" educator' (Smith \& Campbell, 2018). As Blaise (2005) argues, an educator who properly demonstrates DAP likely feels confident in their position and is seen by others as a knowledgeable educator. Good educators are often those who are "constituted within circulating discourse as experts who ha[ve] special insights into the true picture of who each child was, the child's interests, his or her development, friendships and so on" (Smith \& Campbell, 2018, p.316). For an educator to spend their days making sure that they are completing tasks in order to 'check a box', such as providing portfolios that demonstrate learning and developmental milestones and, evaluating a child's development, educators are positioned as the expert; this is representative of the "good" educator (Smith \& Campbell, 2018). When acting as the "good educator", reproducing developmental 
understandings of children and childhood, it may become hard for the educators to see any other "possibilities for understanding teaching, learning, and young children" (Blaise, 2005, p.3).

Thus, in the end they are both reinforcing the damaging heteronormative discourses for children and likely unable to think critically about the consequences of doing so.

\section{Purpose}

The purpose of this study is to gain insight from knowledgeable ECEs on how they are intentionally incorporating gender fluid discourses (please see Appendix A for a glossary of terms employed in this MRP) in a proactive manner with preschool aged children in early childhood settings. It is important that in this case, that what counts as knowledgeable is not to be understood from a developmental perspective. I do not intend to describe the educator as allknowing--a holder of all knowledge--but it is my intent to describe the educator as capable and powerful (Iorio, Parnell, Quintero, \& Hamm, 2018; Smith \& Campbell, 2018). In this case, knowledge may be this openness to new ideas, the courage to act, to challenge, to think differently, and to change. ECEs are not simply vessels of knowledge but thinkers, capable of challenging, disrupting and changing the status quo (Iorio et al., 2018; Smith \& Campbell, 2018).

The current state of gender discourses in early childhood settings is predominantly centred on heterosexuality, which has proven to be both limiting and damaging (Gunn, 2011). It is not generally known how those working with children are constructing, normalizing or disrupting heterosexuality with children, particularly in the early years (Gansen, 2017). What we do know is that when there is no alternative, children are "faced with normative, linear, heterosexist notions of advancement" (p.69) leaving children with "nowhere to grow (Stockton, 2009)" (O’Loughlin, 2018, p.69). Having only normative ideas represented regarding gender (and class, and race) in ECEC settings is to "either sacrifice desire on the altar of parental and 
societal notions of normative expectation, or else run into the brick wall of developmental arrest and thus be viewed as delayed, deviant or oppositional" (O'Loughlin, 2018, p.70). O'Loughlin (2018) expresses what a grave disservice this is for all children but especially so for the "queer child" (p.70). It is clear that a shift in the dominant gender narratives in ECEC is both timely and crucial.

A second purpose of this research is to promote those working with children as agents of social change. Despite the manner in which they are often represented, I argue that educators are both intelligent and capable. Rather than assuming that academia holds the most valuable information, trying to fill educators with information about theories and practices, expecting that they integrate this into the field without practice, I am instead interested in consulting with educators for this research in order to learn from them what gender fluid practices are already working in the field or what they might recommend to move the field forward. Instead of this idea of a "top down approach" in which I would attempt to bring academic theories and knowledge to ECEs, I instead apply the opposite, utilizing a "bottom up approach" in order to learn from the ECEs and bring this to academia instead. I hope to unsettle heteronormativity in early childhood settings and help bridge the theory / practice gap. Through conversations with knowledgeable educators, I hope to learn how to provide a variety of alternative ways of addressing and supporting gender in the classroom, some of which may require taking a risk and challenging long standing assumptions (Blaise, 2005; Gunn, 2011; Kroeger, Recker \& Gunn, 2019; Nxumalo \& Adair, 2019).

\section{Importance of research}

ECEC settings are places of unique opportunity as children are working to figure out and build their own gender identities using what they are seeing and experiencing around them. 
Conversations and comments about gender show up all throughout a child's day. This may happen through conversations with their peers, adults or take place within themselves (Robinson, 2013). For the many reasons stated in this paper and beyond, it is important that the developmental discourses taking place in early childhood settings be questioned, challenged and revised.

Postdevelopmental theories provide alternative perspectives to dominant discourses currently used in ECEC settings (Berman \& Abwai, 2019). Blaise (2009) defines postdevelopmental theories as "alternative theoretical perspectives that question modernist assumptions of truth, universality and certainty" (p.452). Therefore, postdevelopmentalism rejects developmental understandings of sex and gender and for that reason, are helpful when looking for more supportive ways of responding to gender in ECEC settings. Postdevelopmental theories are important to this project as I hope to reconsider how gender is understood and supported in ECEC classrooms by ECEs. The use of Queer theory to address gender in early childhood is not new, but in my review of the research and based on my lived experience, the evidence of taking up ideas from this theory in practice continues to be few and far between.

This will be an inquiry into the valuable and brave work already being done by ECEs in the field. It is my hope that this work is able to connect readers with working real life examples that are already being put into place that respect the complexity of children's lives and provide practical support to children and families, while challenging the dominant discourses circulating in society as we continue forwards.

\section{What is the gap?}

There is an abundance of valuable literature written on the topic of gender in ECEC settings. This literature discusses the shortcomings of developmental theory in supporting 
children in their exploration and experiences of gender and recommends implementing alternative theories in order to help support children (See: Blaise, 2005; Blaise, 2009; Breneselović \& Krnjaja, 2016; Gunn, 2011; Kelly-Ware, 2016; Lyttleton-Smith, 2017; Mackenzie \& Talbott, 2018; Martin, 1998; Robinson, 2013; Stafford, 2016; Wingrave, 2018). Although a majority of the well-established research literature on this topic has taken place in the UK and Australia, their influence, along with an ECEC field that tends to pride itself in inclusion and openness to diversity, should represent a shift in Canadian ECE practice. Yet, unfortunately, this does not seem to be the case.

\section{Research question}

How are Early Childhood Educators intentionally incorporating gender fluid discourses into their classrooms?

\section{Road map}

First, I discuss the frameworks that I have used to think about this project in order to help situate the reader. This is followed by a review of the literature on gender practices and discourses within the ECEC field that provided the foundation for this study. Next, the methods essential to this study are presented in order to support the remaining two sections, the findings which present the data shared by the participants, and lastly, the project concludes with the discussion, strengths and limitations, and suggestions for future research. 


\section{Conceptual and Theoretical Frameworks}

I began this project thinking with Queer theory as the ideas and language within this theory supported me in learning about dominant discourses and gender fluid discourses in ECEC settings. In developing my ideas further, I realized that in a broader sense, I am taking on a social justice approach in order to address the lack of critical pedagogies taking place in ECEC settings and encourage educators to engage with these pedagogies. This approach fits with the reconceptualist (RECE) thinking that I have been engaging in, as the RECE movement strives to reconceptualize research, theory, policy and pedagogies in ECEC (Bloch, Swadener, \& Cannella, 2018).

\section{Queer theory}

This project was informed by Queer theory and could not have been drafted or carried out without the use of the language and ideas of this theory. Queer theory, which was born from post-structural and feminist perspectives, critiques the gender binary and goes beyond simply challenging these gender binaries by also bringing sexuality into consideration (Taylor \& Blaise, 2007). Queer theory aims to deconstruct the notion of heteronormativity in which heterosexuality is considered the universal norm and therefore, any act, including play for example, that falls into this category is deemed as the 'natural' way (Taylor \& Blaise, 2007). Heteronormativity negates the opportunity to question these acts and this contributes to the reinforcing of stereotypical gender roles (Taylor \& Blaise, 2007).

\section{Critical Paradigm}

For this project I am working within a critical paradigm. Leavy (2017) defines critical paradigm as "a philosophical belief system that developed in interdisciplinary contexts, including areas studies and other fields forged in critique (e.g., women's studies, African American 
studies), and that politicizes research and emphasizes power-rich contexts, dominant discourses, and social justice" (p.251). The social justice approach that is taken in this project fits nicely within this critical paradigm. One way to undertake a social justice approach in ECEC settings is to "draw inspiration from critical pedagogy (Freire, 1999) and its strength-based, sociopolitically situated and action-oriented engagements with teaching and learning" (Nxumalo \& Adair, 2019, p.669). Unlike traditional theory that tends to reinforce and explore already established norms, critical theory aims to challenge these norms while striving for a "balanced and democratic society" (Asghar, 2013, p.3123). By challenging the use of dominant discourses in ECEC settings, critical pedagogy provides "actionable tools for interrogating and resisting oppressive power relations" (Nxumalo \& Adair, p.669). This focus is also often concerned with power in social systems and constructs, including gender (but also class, race, education, religion, economy, and so on), making a critical paradigm a good fit for this project (Asghar, 2013). Bohman (2013) follows Horkheimer's (1982) criteria for competent critical theory, and the three points are as follows "it must explain what is wrong with current social reality, identify the actors to change it, and provide both clear norms for criticism and achievable practical goals for social transformation" (Critical theory section, para. 3). As with this project, a critical paradigm not only identifies the issue but also explores the possible avenues necessary to incorporate a wide variety of possible solutions into practice that would contribute to improving current social systems (Asghar, 2013). Barnikis (2015) explains that critical pedagogy was developed from critical theory as it "can be employed to challenge familiar everyday values and practices, within school systems, by exploring the relationship between power and knowledge, and by recognizing that knowledge is socially constructed and is deeply influenced by power structures" (p.292). 


\section{CHAPTER 2. LITERATURE REVIEW}

The purpose of this literature review is to synthesize recent research on the topic of gender. More specifically, it synthesizes literature on how gender gets constructed and is policed in ECEC settings and why. This literature review considers the current gender discourses in ECEC and demonstrates how they have proven to be inadequate and even harmful when working to support children and gender in ECEC settings. The literature also considered what a shift in these discourses might look like and highlights the positive effects and alternative possibilities that may arise when this shift is considered and implemented in practice. This literature review identified a gap in bringing these alternative discourses and gender perspectives to the field and presents possible solutions in bridging this gap that are important to consider for this project. This literature review will continue the conversation on the important theoretical underpinnings of this project and serves to establish the value of integrating them into ECEC practice, the disservice caused by continuing as we, are and the need to find different ways of making this shift happen.

\section{Dominant Discourses in ECEC}

Child development is responsible for how "childhood, teaching and learning" (Blaise, 2009, p.451) are understood and practiced in ECEC settings. This means that what educators notice in the classroom, how they choose to respond and how they offer support to children is most often done so through a developmental lens (Blaise, 2009). Developmental psychology is used to understand children and to "assess where each child [is] at socially, emotionally, cognitively, and physically" (Blaise, 2005, p.2). The goal is to meet children's individual needs and in order to do so child development focuses on "four main categories: cognitive, language,

social/emotional and physical abilities (Almy \& Genishi, 1979; Bredekamp \& Copple, 2009. It is 
through these four categories that educators will then assess each child's development and create a program based on their individual needs (Blaise, 2005).

The omnipresent influence of developmental theory in ECEC means that it is also the perspective responsible for explaining complex social issues that the theory is not equipped to handle, such as gender. From a developmental standpoint, a child is simply born with both their sex and their gender and this is something that has been biologically determined for them (Blaise, 2009). From this biological standpoint, gender is innate (Gunn, 2011) and can only be explained through a strict and limiting binary. The gender binary is a powerful cultural ideology or "truth regime" that is accepted by society as absolute, inarguable truth (Foucault, as cited in Rahilly, 2015), and the gender truth regime can begin as early as an ultrasound or the moment a child is born. Once their sex is assigned, "the gender binary establishes a set of cultural presumptions about one's gendered preferences and expressions" (Rahilly, 2015, p.356). In ECEC settings, gender is traditionally understood within these developmental and biological viewpoints, considering only a strict boy / girl binary that is based on the sex of the child and produces "naturalised differential expectations for the behaviors and emotions of boys and girls (Burman, 2008)" (Lyttleton-Smith, 2017, p.3).

Unlike child development theory, heteronormativity is a term that is highly unlikely to be found in the textbooks of preservice educators. Despite the lack of conversation addressing heteronormativity in preservice education, it is equally as pervasive within ECEC settings and therefore, also a dominant discourse within ECEC settings. Heteronormativity is a concept that places heterosexuality as not only the norm but the "superior and privileged standard" (Gunn, 2011, p.280). Heteronormativity places heterosexual sexuality as "constructed as natural, as unquestionable, and as taken-for-granted" (Gunn, 2011, p.281). The normalization of 
heterosexual discourses has significant consequences for children, educators and parents in ECEC (Gunn, 2011). When heterosexuality is held as the standard in ECEC, heteronormativity "encompasses the related concepts of gender, sexualities and family form" (Gunn, 2008, p.106). Thus, meaning that discourses surrounding family, sexuality and gender are closely tied with heterosexual discourses without considerations of any possibilities that may fall outside or challenge the heteronormative.

Heteronormative stereotypes and expectations need to be taken seriously as they can result in negative consequences for children. For example, children may be afraid to push beyond the gender binary even when they feel as though it is important to them. Many children want to fit in and will work to make sure that they will fit within the gender binary by learning what is and what is not appropriate (Breneselović \& Krnjaja, 2016). This practice in exclusivity leads to discrimination, gender segregation, rigid rules and prejudices (Breneselović \& Krnjaja, 2016; Lyttleton-Smith, 2017). Both researchers and educators "have expressed concern regarding the negative impact that the heteronormativity of schooling has on children's self-esteem, levels of social tolerance, and attitudes towards relationships and sexuality" (Lyttleton-Smith, 2017, p.4). These consequences will be discussed in further depth later on in the literature review.

\section{A Shift in Ideas}

As stated at the outset of this Master's Research Paper, reconceptualist scholars have been critiquing developmental theory and pushing for a shift in ECEC discourses for almost thirty years (Lubeck, 1995). These scholars are of the belief that child development theory is a biased "modern, middle-class, and Western discipline" that "universalizes the child and childhood" through its individualistic nature (Blaise, 2009, p.451). This universalization of childhood reinforces the developmental understanding that children develop 'naturally' (Blaise, 
2009). The image of the 'naturally developing child' (James, Jenks, \& Prout, 1998) is what is represented within developmentally appropriate practice, an image which neglects to address the complexities of children's lives including just how much gender impacts children's lives and experiences. Therefore, reconceptualist scholars believe that alternative, postdevelopmental perspectives must be considered in ECEC settings in order to better support children's gender exploration.

The heterosexual matrix was developed by philosopher Judith Butler (1990) in order to help identify the heteronormative discourses that are present. The heterosexual matrix contains the invisible norms that are responsible for dictating how girls and boys should behave and look in order to properly perform their genders to the standards of heteronormativity. For example, when living within this matrix, girls wear dresses. When a child who identifies as a girl follows these rules they are likely to receive positive feedback, if a child who identifies as a boy were to wear a dress, he would likely receive negative feedback. This is how the heterosexual matrix works to dictate and enforce what is and isn't appropriate for each gender. In ECEC settings, the heterosexual matrix can be used to help make obvious how gender is played out in the classroom, how children are demonstrating stereotypical gender roles and why it is important to them (Paechter, 2017). Using the heterosexual matrix as an alternative point of view for educators in the classroom encourages a shift in perspective and helps to uncover just how much of an impact heterosexual discourses has on how the social order of the classroom is organized and enforced (Blaise, 2005; Paechter, 2017). Thus, in ECEC settings, new meanings begin to emerge on how both children and educators are doing gender (Blaise, 2005), encouraging educators to consider alternative perspectives to uncover what other discourses are taking place in their classrooms and how they are having an impact. 
Using alternative postdevelopmental theories such as Queer theory to address and discuss gender in ECEC with children is not a new idea. Dr. Mindy Blaise is an early childhood scholar who has focused a large part of her career trying to use Queer theory and feminist poststructuralism to challenge developmental theory and reconceptualize gender in ECEC settings. Blaise shares honestly the challenges of implementing new theories in ECEC settings and that "it is always difficult to teach against the dominant discourses of education" (2005, p.33). Nonetheless, the risks and challenges are not wasted, Blaise (2005) refers to this work as necessary as the implications of not taking these risks far outweigh the challenges. Unfortunately, the magnitude of this difficulty was demonstrated by Blaise as she shared her frustration with the lack of new theories being implemented into ECEC settings since she has begun her work (personal communication, 2019). Indeed, in more recent years, she has moved away from the study of gender, as she felt that even with the number of people who were trying to do the work of incorporating Queer theory and feminist poststructuralism into early childhood settings, she did not feel like these approaches were showing up in the field, and she kept hearing the same stories repeating themselves (personal communication, 2019).

That being said, in March of 2019, The National Association for the Education of Young Children (NAEYC), the organization responsible for creating and encouraging DAP since 1986 (Silin, 2018), published an article on re-thinking gender in ECEC settings and how to take different approaches to gender. The article, written by Kroeger, Recker \& Gunn (2019) presents alternative perspectives of gender, how they can be incorporated into ECEC settings and various tools and suggestions for ECEs. This exciting shift coming from an organization who once were "implicit in the absolutist manner in which [they] held on to the developmental canon" (Silin, 
2018, p.64) is perhaps enough evidence that this fight has not been for nothing and hope for further progress in alternative perspectives, including gender, lies ahead.

\section{Limitations of the current heteronormative developmental discourses}

As a result of living within the heterosexual matrix, both peers and ECEs frequently reinforce the representations of heteronormative gender roles in early childhood settings. Due to the constant reproduction of these roles, they become known as 'truths' in the classroom (KellyWare, 2016). Children are thus encouraged to maintain stereotypical gendered roles, which have proven to be highly exclusive. This is due to the limiting nature of the dominant gender binary (Blaise, 2009), "Teaching towards [this] gender binary" often fails to recognize the child as an individual who holds individual experiences with gender that may differ from one child to the next (Stafford, 2016, p.29). The gender binary considers only two options, girl or boy and places the two options in opposition of each other (Prioletta, 2018). Many examples of this girl / boy divide are demonstrated in the following paragraphs.

\section{Outside influences}

A number of studies on this topic found that both educators and children perceive that some activities and toys are only for girls or only for boys. Amongst these recent examples were educators (situated around the globe in Serbia, New Zealand and USA) who believed that vehicles are strictly for boys, that only boys enjoy physical activity and rough and tumble play, and that hairdresser, kitchen and doll play are not acceptable for boys to take part in (Breneselović \& Krnjaja, 2016; Kelly-Ware, 2016; Mackenzie \& Talbott, 2018). When boys dare to break these unwritten rules, such as feeling joyous when dressing up in a gown and a wig, receiving harsh feedback from peers is not uncommon (Kelly-Ware, 2016). For children who 
identified as girls, the most common assumptions were that they enjoy dressing up, enjoy being quiet, or talking amongst other girls (Breneselović \& Krnjaja, 2016).

It is important to note that these stereotypes are not only reinforced by peers but by educators as well. For example, when one of the teachers in Lynch's 2015 article, speaks of using math to interest the boys, she describes the girls as "scared" of it. Building on this differential treatment, girls are also more often sexualized from a young age and although it is common for teachers to give different praise for different genders, girls are more likely to receive compliments based on their clothing, hair and good temperament whereas boys are more likely to receive compliments based on their physical size (Lynch, 2015).

Parents are another significant factor that need to be considered due to the influence they sometimes hold in ECEC settings. This influence is two-fold; first, parents in the Western world play a large role in dictating what should and should not be taught in regard to gender and sex education (Robinson, 2013) and second, the fear that educators hold over "parents' objections based on cultural and religious values or conservative worldviews" (Robinson, 2013, p. 66). Robinson established that it is this fear that dictates how sexuality is discussed with children in ECEC settings or if it even is discussed at all (Robinson, 2013). Both educator and parent influence has to do with the "discourse of adults knowing what is best for children" (Robinson, 2013, p.66), and this has a significant impact on children's agency. This lack of agency is especially troubling in reference to gender identity and exploration in which the child is left without much freedom or say.

\section{Gendered spaces}

An example in a Canadian (Québec) classroom (Prioletta, 2018) demonstrates how many early childhood settings offer activity centres that are often marked as feminine or masculine 
through the heterosexual matrix, for example, the home/kitchen centre, which is often marked as a feminine centre and the block centre, which is often marked as a masculine centre. Under the influence of these heteronormative designations, many children "play in spaces and with toys that seem socially acceptable for their sex and gender" in order to simply 'get it right' or 'be normal' (Prioletta, 2018, p.82). This is a distinct example of the heterosexual matrix (Butler, 1990) at work in the classroom. Power dynamics between boys and girls may also have a significant influence on where children choose to play, "girls may feel safe, powerful, and in control in spaces like the kitchen centre" and may choose to avoid centres that are often controlled by boys in order to "avoid being dominated by boys" (Prioletta, 2018, p.83). Breneselović \& Krnjaja (2016), observed children's play in which the boys stated that they are not restricted from going anywhere or doing anything in the room simply because they are boys, whereas the girls involved in the play were encouraged to play the part of the "slave". As Prioletta explains, "gender works to govern where a child can play" (2018, p.85).

\section{Hidden curriculum}

Martin (1998) discusses the "hidden curriculum" in connection to the restriction to gendered bodies in the classroom. Hidden curriculum is the recognition of the lessons children are learning while in school settings that are not part of the academic curriculum being offered ("Hidden Curriculum," 2015). It is referred to as hidden because "it is usually unacknowledged or unexamined by students, educators, and the wider community" (para. 2) thus, reinforcing the accepted norms of the status quo, such as dominant discourses ("Hidden Curriculum," 2015). Martin demonstrates how the hidden curriculum works to reinforce gender relations through "gender presentation, monitoring, and interpretation of bodies" (1998, p.495). Depending on the success of these presentations, certain bodies will be disciplined within education settings 
(Martin, 1998). This form of "social control" serves to not only control children's bodily movements but to form children into 'proper' girls and boys (Martin, 1998). Martin argues that the different rules, instructions, expectations and discipline for children based on their perceived genders result in forming docile gendered bodies that will fit within the gender binary, thus, significantly limiting any other possibilities. The review of the literature makes clear that children are quick to pick up on their environments and how they are being treated. With such gendered treatment surrounding them, they too will begin to organize themselves and others based on these ideas, further encouraging a strict gender binary, resulting in further inequities (Wingrave, 2018). It is clear that this process would also result in consequences of further gender segregation (Wingrave, 2018).

\section{Making sense of these messages}

Young children are not only internalizing messages about heteronormativity and gender roles via the hidden curriculum of the heterosexual matrix but will also use them to build their own social preferences and judgments of others (Shutts, Kenward, Falk, Ivegran \& Fawcett 2015). Gender policing, or as Blaise (2014) describes it, "category-maintenance work" (p.321) is prevalent throughout all areas and interactions of the school day, leaving young children using it as a tool in order to make sense of both their own gender identities and the gender identities of others. In other words, children are using the heterosexual matrix in order to make sense of what is and isn't appropriate for certain genders, leaving any actions or behaviors that may fall outside strict heteronormative ideas to be easily 'punished'. Schools and childcare settings are often seen as places of acceptance and belonging, therefore, they should not be another place where gender inequities are patrolled and enforced (Mackenzie \& Talbott, 2018). This monitoring results in some children being deemed of less value, and when these beliefs about self-worth are 
instilled in early childhood, they may likely follow a child through school and later adulthood (Mackenzie \& Talbott, 2018). Such children are also bound to suffer emotional and social consequences such as bullying and exclusion from their peers (Lynch, 2015).

As children make important decisions that are based on the messages they receive, and use these as they construct their identities and sense of self, Breneselović \& Krnjaja (2016) recommend that while making these decisions, children should not be left to work through the "gender stereotyping encouraged by society" (p.63) and that educators need to both "support and encourage them through that process" (p.63). When children are left to themselves to work through these issues on their own, their sense of self, "ways of being" and agency are all compromised (Kelly-Ware, 2016). Children are more likely to accept these messages and consequences when they do not receive the necessary support from the adults in their lives. Educators are especially influential as they are in the unique position to support and encourage gender conversations with children in ECEC settings. As discussed in this section, the assumptions based in heteronormative ideas of gender, often lead to serious consequences and it is important that they be addressed. As Blaise (2009) argues, instead of limiting ourselves within developmental frameworks, frameworks that have proven themselves entirely inadequate in responding to gender and sexuality in childhood, it is time that the field of ECEC take up new perspectives. The NAEYC publication on alternative perspectives and approaches to gender that was mentioned previously, demonstrates the readiness of a significant influential body such as NAEYC to discuss and present alternative perspectives and demonstrates the urgency to acknowledge that the field must start incorporating new ways of thinking about gender. (Kroeger, Recker, \& Gunn, 2019). 


\section{When Alternative Theories are Considered}

Contrary to the consequences tied to the reproduction of dominant gender discourses, there are a number of positive changes that occur when utilising gender fluid discourses in the classroom. With the support of alternative theoretical perspectives, such as Queer theory, we are encouraged to imagine gender as a social construct and a flexible concept. When understanding adults are able to provide support in this area, it may help children begin to see personal benefits. Utilizing agency is a major benefit that may also encourage equality between genders and also help combat power dynamics (Blaise, 2014; Kelly-Ware, 2016). Through gender fluid discourses, children can learn inclusive and important skills such as determining what is fair or just, and inclusive (Kelly-Ware, 2016). Working from a developmental perspective ,Mackenzie and Talbott (2018) demonstrated that children have shown higher self-esteem, confidence, acceptance and happiness. This was demonstrated in an example in an article written in which a young child shares their thoughts on what would happen if people stopped telling children what to wear, what colours to wear or who they are (Mackenzie \& Talbott, 2018). The child explained that if these things stopped then "kids wouldn't be sad" (Mackenzie \& Talbott, 2018, p.661).

When heteronormative gender narratives are disrupted, and children are supported and encouraged to play with toys and do activities outside the gendered expectations, gender fluid discourses "may help support children whose interests or skills do not fit into such a binary pattern, enabling greater freedom of expression outside of gender expectations" (LyttletonSmith, 2017, p.14). Adopting gender fluid discourses also demonstrates inclusion for families who may fall outside of the strict heterosexual gender binary, and for children who are growing up in these families, this is crucial. Surtees and Gunn (2010), demonstrate this through the example of children talking about how girls don't kiss each other and another child whispers that 
her moms' kiss each other, an example that shows how children from these families are being excluded when classrooms are using only heteronormative discourses.

The recent push by some early childhood scholars to create a shift in the developmental discourses of the ECEC field and move towards ideas taken up in the sociology of childhood not only make obvious the importance and value of children's agency but the lack of it within current theoretical frameworks. As Blaise (2009) explains, agency comes from a lack of power, a position that children automatically find themselves in. Agency has a lot to do with power especially in how it concerns an individual's ability to act and have an effect, and this is also applicable to gender discourse (Blaise, 2009). When we encourage a gender fluid discourse, children have the space to do and act out their genders through masculinity and femininity as they see fit. When this agency is encouraged for children and they are given the space to explore, they have the opportunity to truly find out what it means to be a girl, a boy, or however else they may choose to identify, and what that means to them (Blaise, 2009). In restoring agency back to children's own processes of identity, we are showing children that we consider them as human beings and are respecting their human rights.

Shutts et al.'s 2017 study demonstrated how a gender fluid pedagogy created opportunities for new bonds between children of different genders who wouldn't have interacted otherwise. A gender-neutral pedagogy works to devalue assumptions and judgements that are made about other genders, in turn, breaking down significant barriers (Shutts et al., 2017). When children stop using gender as an area to place judgements, they become open to new relationships (Shutts et al., 2017). When adults have the necessary skill to critically dismantle gender stereotypes in the classroom setting through both conversation and available materials, the focus shifts and a more inclusive community emerges (Shutts et al., 2017). 
A large part of the work in deconstructing gender norms involves the redistribution of power and this can happen in different ways. One of these ways addresses some of the power dynamics that take place amongst different genders. This is important as using stereotypical gender discourses tends to result in unequal opportunities for all children. Adopting gender fluid discourses immediately begins the work of dismantling this inequality, resulting in equal opportunities for all children in the classroom (Lynch, 2015). Ideally, children who identify as female would no longer be thought of as inferior, more docile and easier to please than their male classmates (Wingrave, 2018). When we open up the concept of what is acceptable in our classrooms, children of all genders have the opportunity for so much more exploration and learning that will have a positive effect on their childhood and lives overall (Wingrave, 2018). Adopting a gender fluid discourse in the classroom can help break the inequity of power and distribute it more equally amongst all children and families (Blaise, 2010).

Paechter (2017) believes that in order to "claim agency as active citizens" children will seek to fit themselves within the heterosexual matrix. In their reproduction of heteronormativity, children are resisting alternative discourses in order to help claim themselves as similar to adults and feel as though they have access to feelings of power (Paechter, 2017), feelings that are often lacking for children. Paechter (2017) argues that in order to remedy this, the power needs to be taken out of heteronormativity in the classroom. By leaving space and giving opportunity for children to have power in other areas, the need to prove themselves within the matrix may decrease.

\section{Disconnect Between Theory and Practice}

There is a considerable amount of literature discussing the demand for a shift in how the field of ECEC is both thinking about and incorporating gender into their practice. With the 
amount of literature produced on this topic, it would seem that the work of incorporating a gender fluid discourse for children may be already achieved or in the very least, well on its way. With such rich information and observations already out there, we would expect that this would be reflected in practice. Unfortunately, this does not seem to be the case. Due to dated and limiting pervasive developmental perspectives that have been discussed throughout this paper, it seems that shift in gender fluid thinking in practice is far behind the literature (Kelly-Ware, 2016). Again, with NAYEC publishing an article that supports a shift in the discourses in March of 2019, it is hopeful that this is beginning to change (Kroeger, Recker \& Gunn, 2019).

As previously discussed, as developmental psychology is the foundation for the field of ECEC, this is the thinking that ECEs are bringing to their practice (Pacini-Ketchabaw, 2006). Developmental psychology is often the only theory practiced in an educator's education, and therefore, children are grossly oversimplified and understood as "naturally developing" beings (James et al., 1998). Also as discussed, the universalization of childhood does not address the value of gender or sexuality in children's lives. The result of this may be educators who are then unequipped to be supportive, to have necessary conversations, and interactions with children regarding their gender and sexuality (Blaise, 2009). This continues in a cyclical motion, if educator training continues to be informed through DAP research, educators will not have the education and training that would be required to challenge developmental perspectives and push past them. Stereotypical gender norms will be reproduced without question within the classroom and thus, they will continue to be normalized (Blaise, 2009; Kessler, 2018).

Breneselović \& Krnjaja's (2016) study demonstrated that the culture found in early childhood environments frequently reinforces the stereotypical gender norms rather than challenging them. Breneselović \& Krnjaja (2016) are clear in stating that differing gender themes 
are present in early childhood environments, but children are left to construct and define what they mean without the support of adults, which often results in gendered stereotypes.

In studies that looked at centres where educators did believe in using gender fluid pedagogies and were both knowledgeable and well equipped to handle the task, their actions did not reflect their spoken ideals (Warin \& Adriany, 2017). In Warin and Adriany's 2017 study, only one teacher from each group was truly able to have their beliefs about gender fluid discourses reflected in a positive way through their teaching practices. It seems as that even when teachers and ECEs have received some sort of training in gender flexible pedagogy, and work hard to partake in critical thought, they tend to continue to struggle demonstrating gender fluid discourses within their practice in early childhood environments (Warin et al., 2017).

Improving this state of affairs would not be an easy task, as there are many areas to consider. Some reasons for this that were demonstrated in the literature included gender fluid discourses requiring somewhat of a shift in most (if not all) of the areas of the program and this would require many resources, such as time and money (Warin \& Adriany, 2017). It would also require consciousness on the educator's part (Warin \& Adriany, 2017). For educators to think critically of the dominant discourses and reconsider their practice to rethink gender, they must be able to practice thinking and reflecting critically and be able to easily identify the pervasiveness of gender norms that will persist and continue (Warin \& Adriany, 2017). Beyond reviewing educator's pre-service programs, it is important to also consider that all educators are coming into the field with their own belief systems. These belief systems are often very deeply rooted, which in turn, makes them hard to shift without the time and capabilities for deep thought, reflection and critical thinking (Warin \& Adriany, 2017). Shutts et al. (2017), discovered that there is also an issue in accountability and feeling powerless in making a difference. Wingrave 
(2018) found that the teachers in her study believed that children received their information on gender from other places and expressed that they felt there was not much they could do to have an influence.

There are many examples of this disconnect in the literature. Shutts el al., (2017) bring attention to the way that teachers organize their classroom by gender for example, seating the children in an alternating 'boy', 'girl' pattern. Teachers will also often use the same types of patterns through transitions and activities to help ease the process (Lynch, 2015). It is easy to see how these comments may have an impact on children however, Lynch (2015) states that the vast majority of teachers did not seem to realize that comments such as these were encouraging gender stereotypes. In Prioletta's exploration of preschool teacher's beliefs of equality in the classroom, the author found that teacher perceptions of gender separated play was not due to gender inequalities but instead a 'function of girls' and boys' assumed natural preference for playing at particular centres" $(2018$, p.85).

In order to address this, Lyttleton-Smith recommends "de-zoning activities" through classroom reorganization in ways that "disregard or question 'common sense' gender associations" of certain activities or play areas $(2017$, p.14). The early childhood education field often prides themselves on their openness to diversity, difference and inclusion (Surtees, et al. 2010). Therefore, it is alarming that this disconnect still persists today. It is important to also remember the fear that educators often experience due to push back from parents that was discussed previously, having proper policies in place in the centre would help mediate this fear (Robinson, 2013). It is clear that educators will require further education and tools to be able to provide for children in the way that is required (Warin et al., 2017). Although difficult, the literature offers meaningful pathways towards incorporating a gender fluid discourse in the 
classroom, such as incorporating picture books and reading them critically with children, and facilitating discussions with children about gender (Farley, 2017; Gagliardi, 2014).

If educators are provided adequate tools, this may alleviate some of the feelings of powerlessness and encourage accountability (Wingrave, 2018). Ongoing training, insight and critical thought for educators may help provide a "socially just, stimulating and creative learning space for all children" (Wingrave, 2018, p.602). Kroeger and Regula (2017) suggest that "antibullying" models are insufficient when responding and supporting children's gender and sexuality. The authors suggest that along with teaching preservice ECEs about "inclusive strategies", a combination of "a more complex understanding of the biological development of children" and "the de-construction of the male-female binary" may be successful (Kroeger \& Regula, 2017, p.109).

\section{Summary}

Dominant discourses in ECEC settings are pervasive and leave little room for alternative perspectives resulting in significant consequences for children who frequent these settings. The literature illustrates that it is important that gender in ECEC settings be reconceptualized and alternative perspectives be considered. This is due to the many positive changes that arise when critical thinking is used to consider how gender is happening in the ECEC classroom. Although the literature does exist on the negative consequences for children and educators that the prevalence of dominant discourses often generates, and on the positive impacts of shifting these discourses, the literature demonstrates that this is not something that is often reflected in ECEC practices at this time. 


\section{CHAPTER 3. METHODOLOGY}

\section{Approach}

I employ a qualitative approach in this study, as my goal is to explore "depth or meaning and people's subjective experiences and their meaning-making processes" (Leavy, 2017, p.124). This makes for an ideal approach when wanting to explore participants' personal relationships with gender fluid discourses. More specifically I will adopt a phenomenological approach as I am interested in the personal perspectives and ideas of educators in the field. A phenomenological approach puts emphasis on the way people understand and interpret their own lives and experiences (Bryrne, 2017; Leavy, 2017). Thus, this approach is crucial to the nature of this research as I am looking to gather the ideas and perspectives of the educators in a focus group.

As far as data gathering techniques, a focus group and a phone interview were employed. Focus groups can allow participants to talk honestly and openly about what they feel is important using their own language, with the opportunity to share stories and experiences with other participants who may have shared some of the same experiences (Leavy, 2017). As I was hoping to hear as many rich ideas on how to incorporate gender fluid discourses as possible, I thought that a focus group would generate more ideas, as the participants would have the opportunity to interact and build on each other's ideas. Further reasoning behind why I selected focus groups as a data collection method is discussed in the ethics section. Because one of my participants was recommended to me by my supervisor (Dr. Rachel Berman) as being a good fit for the study and because she did not have time to participate in the focus group session, I opted to do a phone interview with her. This phone interview could then be used to inform the focus group session. 


\section{Researcher positionality}

In Winnipeg I am a registered ECE III, with a BA in Child Development Studies. I had practiced as an ECE in the field of ECEC, with children of all ages for nine years prior to beginning this project. Although I may not hold many of the same beliefs as my undergraduate program or ECE program, I believe that these programs, along with my work experience have given me adequate knowledge to have these conversations with my participants and help me share some common ground with them. My personal interest in social justice has led me to many elective courses that focused on gender and sexuality, and the information gleaned from such courses has guided and encouraged me to want to bridge these two fields (cultural studies and ECE) together and work towards seeing this reflected in practice. I believe that my purposeful sample of ECEs have likely been on different, yet similar journeys that have lead them to a similar position. Because I am using a purposeful sample of participants, I likely hold many of the same views as my participants. In order to help mediate bias, I used direct quotations rather than summaries in this MRP. I cannot assume that I have had the same experiences as my participants, but I believe I am equipped to listen, reflect on, and analyze their contributions.

\section{Ethical Considerations}

Before recruiting participants my application to Ryerson University's Research Ethics Board (REB) was submitted and approved. I sought out a location to conduct the research that would likely be without bias towards the outcome of the research or the participants. The chosen location and the considerations of bias are discussed in further detail below under setting. Participants were given adequate information about the research so as to not deceive or mislead the participants, as this is not the purpose of qualitative research. Consent forms (see Appendix 
D, E) were emailed to the participants two weeks before the interview and focus group session. Participants were made aware of how the data would be used and the purpose of the study.

I hoped that the use of a focus group for this project would help diffuse a power imbalance as much as possible. In this method, participants are given the opportunity to lead in the discussion and ask their own questions if they see fit. In order to eliminate any potential risk for the participants, such as risk of their personal identity being exposed, the participants had the option for their contributions to remain confidential. Although this is something that I take seriously, it is beyond the control of the researcher to ensure that the other participants will honour this confidentiality. Participants were encouraged to maintain confidentiality between themselves but in the end, all but one participant chose to use their real first names.

Consent forms were distributed for a second time at the beginning of the focus group session. Beyond indicating the consent of the participants, the forms also indicated that the participants could withdraw their participation at any point and did not need to answer any question or engage in any part of the discussion that they did not feel comfortable with. If they did choose to withdraw their participation, their data would be deleted (as it turns out, there were no participants that chose to withdraw from the study). When signing the consent forms, participants were asked to indicate if they wanted their real names included in this study or a pseudonym. The consent forms are stored in a locked drawer in a locked office. The focus group and telephone interview were audio recorded and then transcribed into word documents. The audio recordings were deleted, and the transcription will be kept in a password protected google drive until the completion of the project in September 2020. 


\section{Recruitment}

Purposeful sampling involves the selection of a limited number of participants that will hopefully provide valuable and rich insight into answering the research question at hand (Emmel, 2014). In taking this into consideration, I was confident that using a purposeful sample fit the purpose of the study, along with the resources, questions, and time constraints (Emmel, 2014). Due to the fact that this project is an MRP that is in partial completion of an MA degree, there is a limited time to complete the project ( 3 months). It was important for me to consider who would be part of the sample "with reference to the purpose of the study, its context, and the specific audience for the research" (Emmel, 2014, p.2). Purposeful sampling requires a careful selection of a smaller number of cases in which it is hoped the most information will be found (Emmel, 2014). Therefore, this research utilized a purposeful sample to ensure that I was involving participants who were currently or had recently, worked with children, believed that utilizing a gender fluid discourse is important, and believed that they had made this a part of their practice. Such criteria for participation appeared necessary in order to answer the research question and allow for having a rich discussion on gender fluid discourses in early childhood settings.

This purposeful sample was achieved through snowball sampling, which involves “asking-well situated people to nominate people who can provide insight into a phenomenon because they know a lot about it" (Emmel, 2014, p.2). Being part of my MA program put me in contact with individuals whom I thought would be helpful in sharing my project with their networks, therefore it was my intent to make connections to key individuals and organizations through this method. I began this process by reaching out to known organizations and individuals who I thought might be knowledgeable on the topic of gender fluid practice and might be aware of other potential participants. I then used this information to locate the research sample. Due to 
the fact that I used a purposeful sample, the size of each focus group was set between three and five participants. As this study used a purposeful sample of knowledgeable people, focus groups of this size are considered sufficient for the purposes of this study.

In order to help recruit participants, a recruitment flyer was used (see Appendix C). The recruitment flyer was distributed through the organization, the 519 community centre, and through email to my supervisor, Dr. Rachel Berman, who forwarded the flyer to her networks, through my own networks in the Master of Arts in Early Childhood Studies program. Word of mouth was also used to locate individuals who would be interested in receiving or distributing the flyer. The recruitment emails were sent out with both the recruitment flyer and the consent form attached. One of the participants had expressed interest in my study when I was in the early stages of drafting the project, and when I reached out to her to see if she was still interested in participating in my project, she was. This participant also shared the study with a colleague and her colleague wanted to participate as well. I was put into contact with two of the participants from Dr. Berman, one of these participants was able to participate in the focus group session and the other did not have the time and requested a phone interview instead, and her request was honoured. One participant reached out to me after seeing my recruitment flyer.

These educators had also indicated at the time of recruitment that they believed the current gender discourses in ECEC are problematic and that using gender fluid discourses with children is important. The educators also believed that they had incorporated gender fluid discourses into their practice. I was originally only looking for registered ECEs (RECEs) who were working in licensed childcare settings, but due to my belief that there would educators with rich ideas and valuable contributions throughout the field I discussed widening the scope of 
eligible participants with my supervisor. After receiving interest from participants who did not fit the original criteria for inclusion in the study, we agreed that it would be worthwhile to change it.

\section{Sample}

In the end, my sample for this study included five individuals who were either currently working, or had previously worked, with children in a child care setting; as stated, one participated in a phone interview, while four participated in a focus group. All five participants filled out a demographic form with information about their educational and career journeys. Because my participants were coming from a wide variety of backgrounds, I hoped that this form would help me better understand my participants and the data they shared. Demographics help to "define the population and therefore the sample" (Frey, 2018, p.2). All of the participants were RECEs in Toronto. Three of the five participants were currently working in early childhood environments, all three of these centres were non-profit. Two of these three were currently working in licenced childcare and the third was working in an unlicensed program These three participants had been working in childcare for ten to twenty years. One of the other participants was currently teaching at the university level and had previously worked in a childcare setting for six to ten years. The remaining participant was working with a professional body affiliated with ECEs and had previously worked in a childcare setting for $10-20$ years. One participant was completing their $\mathrm{PhD}$, one participant was in the process of completing her MA, one participant had completed their MA and the other two participants chose not to indicate their level of education completed. In the consent form, Meredith, Amy, Catherine and Emma all chose to use their real names, whereas Dan opted to use a pseudonym. It is also important to note that I asked each participant for their pronouns and this fact is reflected throughout this paper. 


\section{Setting}

It was important for me to consider the setting of the focus groups as the hope was to achieve high levels of participation with the right environment (Barbour, 2007). Both the phone interview and the focus group session were held in rooms booked at the Ryerson University Library. I chose this location, which was recommended by the reviewers of my ethics application, as it provided a quiet and secure location to conduct the interview and the focus group session, a location that I hoped would make the participants feel comfortable and open to sharing. Snacks and refreshments were provided. The phone interview was held prior to the focus group session. I chose to also book a room in the Ryerson University Library for the phone interview in order to be able to ensure my participant that the call would be kept confidential and to avoid interruption. The dates and times were chosen through consultation with the participants in order to find a time that worked best for them.

\section{Data Collection}

The function of the phone interview was to help inform the focus group session. The phone interview was developed as part of the data collection approach as the participant was recommended as highly knowledgeable by my supervisor, Dr. Berman, but she did not have the time to take part in a focus group session. This participant was emailed the list of questions ahead of time and took part in a thirty-minute phone interview. The questions were meant to act as a guide to the conversation and left room for the participant to discuss what she was comfortable discussing. Because the participant was emailed the questions beforehand, she was prepared to answer them, and it was not necessary for me to ask all of the questions. This is discussed further in findings and demonstrated in Appendix G. 
The remaining four participants took part in a focus group session that was held in the evening and lasted two hours. I had created a script and developed a list of questions that were meant to be followed loosely. The focus group began with an introduction from the researcher and, a description of the purpose and intent of the project (Jayanthi \& Nelson, 2002). I felt it was important to include an icebreaker to begin the focus group in order to encourage participants to open up, participate and get to know who they were talking to (Jayanthi \& Nelson, 2002). I started by asking that the participants go around the circle to introduce themselves, share their pronouns as it is important that my participants' gender pronouns be properly represented in this study, and that the practice of asking people for their gender pronouns becomes normalized as this is something that is currently considered good practice. That being said, it is important to note that this fact is not without debate and when the practice of sharing pronouns becomes forced it can become an uncomfortable practice for some individuals and this should also be considered (Levin, 2018). I also asked how they were located in working with children. My script contained my introduction, a list of questions leading up to the main question, the main question, and a list of questions following the main question. It also contained a selection of semi-structured question suggestions with probes if needed (Jayanthi \& Nelson, 2002; Kvale, 2007). A script that can be loosely followed along with a variety of semi-structured questions is ideal, as it is most important to have the participants voices and ideas come through. That being said, it was important that the questions be somewhat structured as I needed to keep the participants on topic (for the questions please see Appendix H). I was open in my approach by offering the purpose and goal of the focus group as I was interested in hearing their ideas and approaches towards a gender fluid discourse (Kvale, 2007). As I had loosely planned the script ahead of time, I was ready to present probes to the participants in order to keep the discussion 
focused and get the information required for the study (Jayanthi \& Nelson, 2002). Fortunately, the participants were very engaged, and this was not an issue.

The main question was formulated based on the purpose of the project, in which I wanted to find out, from the participants, how they were incorporating gender fluid discourse in their practice (Jayanthi \& Nelson, 2002). It was important that the main question, and any follow up questions that ended up being used, were open-ended and broad as encouraging a rich discussion is the goal (Jayanthi \& Nelson, 2002). The sequence of the questions had also been considered as it was important that I would be able to control both the focus of the discussion and attend to the organization of the discussion so that the data were clear when it came to analyzing it (Jayanthi \& Nelson, 2002).

It was important that my participants were given space to have an open and rich sharing of ideas as I hoped to uncover some powerful examples of what was working in the field. I thought that if these knowledgeable participants had the opportunity to build on each other's contributions, their ideas and examples would grow and improve with the support of a knowledgeable team.

\section{Approach to Data Analysis}

As previously stated, my research question asks: How are Early Childhood Educators intentionally incorporating gender fluid discourses into their classrooms? In order to best answer this question, I thought that the flexibility of thematic analysis would be a benefit as I was unsure as to what kind of examples of gender fluid practices my participants would provide (Braun \& Clarke, 2006). A thematic analysis involves close readings of the transcripts in order to find the repeated patterns or important themes and this was practical in helping me identify what variety of different practices by participants had shared with me (Liamputtong, 2015). 
According to Liamputtong (2015), transcribing the audio recordings is the first step in data analysis as the preparation of data will be required for later steps of analysis. Through transcribing the data, the researcher is said to become more familiar with the data and this is useful when it becomes time to code and analyze the data, which is discussed in the next section. I transcribed both the phone interview and the focus group verbatim, listening to the recordings numerous times at varying speeds in order to ensure that I was transcribing correctly. Thus, every word and expression were included in order to represent the 'true account' of exactly what happened during the focus group (Liamputtong, 2015). I made sure that adequate time was taken to fully understand the data before I began to analyze it, this included reading the transcripts over and taking time to think about what was said (Leavy, 2017). This initial immersion into the data was crucial in supporting the development of ideas and to help prioritize the data for analysis (Leavy, 2017).

Coding was the next step in analysis, this was helpful to both reduce and classify the data (Leavy, 2017). In order to help support answering my research question I started the coding by identifying one overarching theme: ways educators have intentionally incorporated gender fluid discourses into their practice. Once I had coded the data with this initial theme, I began to look for patterns and relationships within the theme (Leavy, 2015). By grouping similar ideas together, I was able to identify reoccurring themes and come up with subthemes. The five subthemes were: (1) Materials that help support gender fluid discourses in the classroom, (2) Practices that help support gender fluid discourses in the classroom, (3) Practices to help involve parents in incorporating gender fluid discourses in the classroom, (4) The Early Childhood Educator and, (5) Changes to ECE education and support. While I was coding, I added memos and notes in order to link the data findings and keep track of how they were helping me make 
sense of the data (Leavy, 2017). The notes included descriptions and ideas about how codes were related, what categories they may fit into and how I might discuss them in the following chapter (Leavy, 2017). 


\section{CHAPTER 4. FINDINGS}

\section{Phone Interview}

Meredith was recommended to me as by my supervisor, but as mentioned, she was unfortunately unable to participate in a focus group session due to time constraints on her end. As mentioned in the methods section, it was decided that I would take this opportunity to speak with Meredith over the phone in a thirty minute phone interview to hear her experiences with gender fluid discourses and have the opportunity to ask her opinion on what I should include in my focus group. Meredith's interview informed the focus group in two ways, indirectly through the sharing of her experiences and directly by me asking what she thought I should include in my focus group.

\section{Indirect influence}

Although my conversation with Meredith influenced me to add four new questions to my list of questions, only two of these questions ended up being asked in the focus group question due to time restraints.

\section{When or what started you on your gender fluid thinking / practice journey?}

Without me asking, Meredith shared how she became curious about learning more about gender and sexuality when talking about her professional and academic journey. This inspired me to include this as a warm up question for my focus group and became the first question I asked. The question sparked lots of discussion and helped the focus group both get started and continue in a direction that was helpful in answering my research question.

\section{Are educators adequately supported in order to respond to children's questions, comments, etc. surrounding gender? Why or why not? How can this be improved?}


In our conversation, Meredith shared moments of her experiences working in the field in which she felt unprepared to respond to children's gendered comments towards her and didn't know what to say. This led me to wonder if other ECEs had had this same experience and I included this question to ask in my focus group question.

\section{Direct influence}

Meredith had a direct influence on my focus group session as I asked her if she had any ideas of what would be important for me to consider before holding the focus group or if there was anything that I should make sure to ask my participants.

\section{Stories}

Meredith suggested that I asked the focus group participants for stories:

I always find it helpful to have them, I like stories, everyone likes stories, so is there a particular story that they might be able to bring into, like the story of Jack [one of the stories that Meredith had shared during her interview], I found that to be probably one of the most powerful things. [...] So, stories about that kind of thing, I think generate the most meaningful dialogues.

In order to incorporate Meredith's advice, as I was introducing the focus group session, I encouraged the participants to share stories and explained that it was because they are powerful ways to share meaning.

\section{Question \#8}

Another direct suggestion made by Meredith was to include question \#8 on the list of questions. The question was: Is there something you had incorporated into your practice that worked? Or something that you now wished you had? Meredith shared:

I think that's a great question cause what I am doing today which looks very different from where I was before, in thinking back I wish I had more confidence to say that there are other ways to be a girl, or there's other ways to wear your hair or other clothes. 
Unfortunately, although I did add this question to my list of focus group questions, I did not get the opportunity to ask it due to both the direction of the focus group conversation and to time constraints.

\section{Focus Group Session}

The remaining findings of this study are reflective of the experiences of the four participants who participated in a two-hour long focus group session. Five themes were established during data analysis. The five themes are: (1) Materials that help support gender fluid discourses in the classroom, (2) Practices that help support gender fluid discourses in the classroom, (3) Practices to help involve and support parents when incorporating gender fluid discourses in the classroom, (4) The Early Childhood Educator, and lastly, (5) Changes to ECE education and support.

\section{Materials that help support gender fluid discourses in the classroom}

This theme incudes concrete materials that were mentioned during the focus group session that could be added to a classroom in order to help support and enhance gender fluid discourses in the classroom.

\section{Having a variety of books with diverse representations of gender and sexuality}

The participants in the study agreed that including books that represented different genders, sexualities and families available in the classroom was important. Emma touched on the tokenistic feel that comes with incorporating books at certain times into traditional daycare settings,

I notice now in my classroom those books are always out, right? and it's that the amount of books that I have grows so there are always books in the space that have different representations of families, one of my favourite books, I don't know if you've ever read it is called Princess of Great Daring. 
It was clear that books were important materials to the participants as they were eager to share recommendations of books with diverse gender representations throughout the session.

\section{Having a variety of dress up materials with diverse representations of gender}

Catherine suggested that including a wide variety of dress up materials for all children be included in her centre as this was a practice that worked for one of her children in the past. Although she shared it took some conversations with her coworkers in her classroom to make sure that everyone was supportive of all children using all dress up materials.

\section{Practices that help support gender fluid discourses in the classroom with children}

This theme includes ways of shifting practice or new methods that were found to be helpful to incorporate into ECEC practice in order to better support or enhance gender fluid discourses in ECEC settings.

\section{Practicing pronouns and gender labels}

Both Catherine and Dan shared that they had worked to include pronouns in their daily practice with children. After hearing from them, Emma shared that she also thought it was important, and would like to take the pronoun practices shared in the focus group back to her centre to use with her group of children. Dan explained how he had incorporated pronouns into his practice:

Everyone at the beginning of the day would announce their pronouns and so then we're not making assumptions about how someone would identify. Every day in our circle we would all announce our pronouns and kids would wear tags that would say their pronouns whether they/them, he/him, she/her and I created space for children to change day to day as well, how they identify themselves and that was really good because what I find in my work is that when you have one child who identifies as gender non-binary and might use they/them, often they are the ones that have to make the extra effort and do the extra work and not only that but they also feel they stand out more and so it's sort of making them feel like they're othered, there's a level of normalization in the sense that everyone is identifying 
their pronouns every day and we're not making any assumptions based on how someone dresses or what their body looks like.

Dan added that conversations around pronouns were also found to lead to having other important conversations about gender such as gendering of things, gendering of play, and gendering of activities.

\section{Reading critically}

Beyond simply incorporating books with diverse representations, Catherine and Emma shared that they like to take the opportunity to challenge and critique books with stereotypical representations and use this to create meaningful conversations with the children. Catherine states:

We'll read a story that has totally stereotypical families in it and I'll say, "okay so what did you notice in that?" Then people will talk a little bit about that - "does that look like your family?"

Emma also shared some of the same techniques in order to point out sexism in children's books and practicing different pronouns by changing them in the story.

\section{Embedded approach}

"I think the embedded approach in terms of my experience is the only one that really makes sense" (Emma), this statement received agreement from all of the participants in the room. Dan shared his take on the approach and how it really made a difference in his practice:

As an educator I've noticed for me that it's in the everyday moments that you show support and in the everyday moments that you shift the discourses and then people, like the parents will take note of that.

Embedding gender fluid discourses did not always need to be complicated. For example, Emma, who was practicing potty training with her children, was asked if a child was a boy because they 
had a penis. Emma replied that she did not know, and that the child should ask the other child instead of assuming. Emma believes this gave the conversation to the children:

So, it became more of a conversation between the children instead of an adult sort of dictating what the gender identity that the child would choose, and it also ended up connecting to a conversation around it's my body it's my choice and the choice piece being I am going to choose how I identify.

What Emma found interesting was that simply making that small change really opened the door to more conversation and transformed the conversation in the classroom. Although simple, Emma shares how embedding these small changes "takes practice" as it is something we are getting used to, even though she admits she grew up having a lot of these conversations. Another way to approach the embedded approach is through critical thinking with the children in the classroom. This is something that Emma practices:

Questioning anytime that one of those: "well she's a girl she should do that." Being like why? Asking the child to deconstruct that statement so anytime that there is a very traditionally sexist comment that is made we deconstruct it; we talk about why they feel that way and a lot of the time they can't tell you. Like well how is this a truth, you know? But if you also like pink and you're a male, you identify as male, how can this be a truth of girls? I find that that conversation, like the critical thinking aspect and the constantly questioning like encouraging them to question the messages that they're receiving is a really, really positive one.

Dan believes embedding gender fluid practices is not all that needs to happen in ECEC settings.

He shares:

It's not just about gender diversity. Like that's part of it but it's the diversity of all sorts of forms of disruption and making people think differently about the world and so I think that's what the field needs and that's not what preservice training offers. [Catherine voices her agreement: yes] When you add on to the fact that there's all these discourses and conversations that try to fit you in a box it makes it really hard, I think. 


\section{Creating space}

A common theme throughout the data was the need to create a safe space for both children and ECEs to explore and learn about each other. The term "safe space" came up when discussing pronoun use and conversations during circle time. Creating a "safe space" includes educators being able to respond to bullying and negative comments that may arise when discussing children's gender and sexuality. The need to create space for children to be who they are was also apparent in the data. In order to create a "safe space" Amy, Catherine and Dan agreed that it was important that the ECE not act as the expert in this situation. Amy shared:

I make it very clear that I'm always learning with them [everyone in agreement: yeah] where it's like 'I'm not teaching you and talking to you, I'm not talking at you, we're learning this together, we're figuring this out together" and so it's being able to create that kind of space in general makes it so much easier for all of these other things to sort of fall into place.

Dan added to Amy's statement:

And yeah, saying "that it's okay to... [change of thought], that you weren't aware of this, now let's talk about it" [everyone in agreement: yeah]

Catherine continues:

Then it's like "hey! I learnt something you guys! So-and-so just told me something, get a load of this!"

Dan:

Yeah and like thinking through it together collectively.

In expressing his concerns, based on both of some of his own personal experience and his educational knowledge, Dan shared:

I think that in particular for boys still we're in a society where if boys are doing things that are seen as feminine, they are devalued, and they are seen as not performing their masculinity in a way that's expected of them and so for me I always think about that in my work. How can I create space for those boys and make space for them to be whoever they want to be because I know I definitely 
did not have anyone back in my corner when I was in school and I think that would have done a lot of good and I think we're dealing with this stuff with toxic masculinity in adults but really deconstructing that stuff starts when you're a kid.

\section{Important conversations (circle time)}

Having important, deep conversations with the children was a reoccurring example that showed up in the data. All of the participants shared that many of these conversations would come up during a "circle time" or group conversation practice that was a significant tool in their ECEC practice. Sometimes the conversations would come up intentionally or unintentionally. Some participants used this time to bring up issues and conversations related to gender whereas in other instances the children used this time to bring it up themselves. In situations where children were the ones to bring gender and sexuality into the conversation it was imperative that the educator be able to support and engage in the conversation with the children. It was often circle time that gave time for the children to share their pronouns. Catherine shared that she is often surprised at "how much [her] six- and seven- and eight-year old's will just sort of quiet down and everybody's listening" when they are having conversations that are disrupting current discourses, such as family constructs. Dan has also used "circle time" to discuss different family structures with children, such as polyamorous families. Catherine shared how it was important to make sure that the children were being respectful:

Having those big conversations with everybody about, you know, you identify as this, okay, so, and then someone might make a little sniggery comment or like a little [whispers] kind of thing and then when we bring it out and say "wait a minute, that's that person's. It's not yours to talk about, it's theirs to talk about" and I think that then we make space for people to be who they are.

Dan believes it's important that ECEs don't wait until children are "old enough" to have these conversations: 
It starts at a young age right, so if you have these conversations with kids about gender at a young age and you really encourage that open conversation and make space for it and you say "nothing's silly, there's not stupid questions, we're just gonna talk about this stuff" and get it open then that has such an impact on those later years too.

\section{Create a program that is a good fit for everyone}

In discussing what works best at the centre she works at, Amy shared how important it was that the activities in the centre did not represent the gender binary and instead supported and engaged all children. This is an idea that the other participants were interested in hearing about and engaging in. Amy shared the reasoning behind why she though this had become an issue in ECEC settings:

I think it's just about people not being open enough and understanding that like it doesn't have to be so cut and dry and it doesn't have to be girls do this and boys do this. [Catherine: like gender divide?] [Dan: Yeah, the gender binary] Exactly, so it's like how do we incorporate both of those things together in these programs that are being developed for these kids?

Later on in the conversation Amy brought up a program that has been happening at her centre that she says she can't take credit for but has supported her children immensely:

I think it's sort of just very, very basic about creating programing that involves everybody and that's something that's happening at our centre this week that's really wonderful and it's just sort of fallen into place.

The specific activity she is talking about it is an individual who is coming into the centre to do basketball camp with the children. With the combination of all of her children having a love for basketball and the inclusive approaches of the basketball coach, things have been building in the classroom. Amy continued:

Everyone is doing all different kinds of activities like it's not the girls are in the dramatic play area, but the boys are there too and instead of playing the games that I often see where it's like the girls are playing and the boys are stealing the stuff from them and they're chasing each other, you know? It's like everybody is working together, everybody is working together in the art area and so it's this 
new thing that's happening really just in this past week, week and a half, where it's working so beautifully where it just looks like the program is catering to everybody and not forcing everybody to participate but almost like really, really encouraging everybody to participate and not having to really encourage too much cause they're all enjoying themselves.

\section{Emma:}

So, are you saying like the team building, because they're providing a team building activity where all genders are included that same team building mentality is transferring?

Amy agrees and also adds that she also believes it has to do with empowering the children. These thoughts bring up ideas for Dan that he shares:

I think for me, the way that I think about it is very similar to universal design for learning, if anyone's heard of that? [everyone replies in agreement] So I think about it in the sense of like you know if you create an environment that's accessible for everyone, you break down barriers to accessing that environment, then you create a safe space for all, right?

\section{Practices to help involve and support parents when incorporating gender fluid}

\section{discourses in the classroom}

Although speaking about parental involvement in terms of gender fluid discourses in ECEC settings was not part of my questions, this is a theme that came up naturally during the discussion. All of the participants had something to add and were eager to discuss their experiences with parents and gender fluid discourses in ECEC settings.

\section{Building relationships and trust}

The most reoccurring idea when discussing how to involve parents in gender fluid discourses and to earn their support was building relationships and trust. All of the participants agreed that building a strong relationship with parents is important in order to earn their trust. The participants believed that once you've earned this trust it makes having the tough conversations easier. Dan shared that building good relationships with his families made it easier 
for him to bring in new materials or conversations that supported gender fluid discourses as he then received parental support. Emma summed up the conversation with an obvious statement:

So hard conversations are easier when you trust the person and have a positive relationship.

The simplicity of this statement received laughter from the other participants. Amy continued by sharing her belief in how helpful having a good relationship with the ECE might be for the parent. Amy states:

It's experience, like having experience working with multiple age groups, and multiple children over a series of years. I mean you have experience so you're able to sort of give that to the parents too.

Emma suggested that another way to connect with parents might be through their children, by teaching the children so that they can teach the parents. Dan found that on top of having conversations with parents, he found it helpful to also send information home such as magazine articles.

\section{The Early Childhood Educator}

Conversations surrounding the image of the educator, self-awareness, privilege, openness, vulnerability and honesty took up a significant portion of the focus group discussion and are discussed in further detail below

\section{Self-awareness}

This topic came about when Emma shared that she had taken one year to deconstruct her own gender, she explained how this "gender voyage" also showed up in her ECEC practice:

The first thing I recognized was how I was modeling, so like every time I would be a construction worker, I realized I was using a very masculine voice and that this was just the beginning of subtle ways that I was reinforcing gender stereotypes in my room. 
Emma said she brought the time she spent thinking about her own gender into the classroom to encourage critical thinking in the classroom through conversations with the children in which she encouraged the children to question the messages they were receiving and deconstruct problematic comments and stereotypes. Emma brought her personal gender questioning into the classroom that sparked conversations with the children:

It turned into "well how do you define yourself? Do you define yourself by your gender? Do you define yourself by your sexuality?" And that's an interesting conversation too because it makes the educator realize what are the hallmarks of my identity that I am portraying because we reinforce those in our work.

Emma admitted that this was something she was able to take part in due to the fact that she was able to shorten her work week from being five days to only four as this is a process that takes time, a resource she explained ECEs are short on. Emma wondered why this time to think about identity wasn't given in preservice education and Catherine agreed:

I totally agree with you, when I was in college and nothing was ever [said] about exploring ourselves or bringing things beyond what they were going to pour into us. They were going to fill us with information and then we were to go out and barf it all out for everybody to absorb and I totally agree with you I think that taking the time to talk to the children is one thing but to really have a sense of where you're coming from in terms of your conversation with the children I think makes the world of difference.

Catherine believes that a lack of self-awareness in the ECEC field is responsible for the poorquality conversations that she would overhear at her centre and that personal self-reflection is what results in meaningful conversations with the children. Emma agreed:

This whole idea that as ECEs it's all about the child and it's all about their needs and their wants I think is BS. I think that personalizing it, making it come from experiences, I think that is really important to me. 


\section{Vulnerability}

Although the participants make it seem that vulnerability can make a significant difference in the conversations with children, Catherine shared how accessing this vulnerability can be a hard thing to do:

There are certain things that your life experiences can inform the conversations in such a lovely way but it's hard because it makes me vulnerable so then I have to make sure that I have to get past the feeling like oh my gosh, this is like, do I really want to pick at that scab? Hold on.

Emma believed that this vulnerability piece was actually one of the barriers ECEs face in engaging in self-reflection:

We're told that everything that happens in the classroom is our responsibility so if we mess it up its our fault and so in doing that it makes you cautious, it makes you not want to be vulnerable, it makes you want to be a robot that is providing services to children and that is not an authentic relationship and so I think that's a big part of it, being vulnerable.

\section{Privilege}

Dan brought the idea of privilege into the conversation and how the discomfort

surrounding talking about privilege has an effect on how ECEs conduct themselves in the field:

It has to do with their own learning as well and so a lot of people have privilege that they aren't aware of as well because when your cisgender and heterosexual then you don't have to think about that stuff and able bodied, and employed like there's just so many ways in which privilege operates and so you don't have to think about something. I think that you don't want to talk about having something that discomforts you because it makes you unlearn your own privileges and it unsettles you and so that's for a lot of people that I've seen push back from what they're pushing back against cause they don't want to have to learn.

Both Catherine and Amy voice their agreements, Catherine elaborates:

Yeah, it threatens their fundamental belief systems and therefore the threads between their identities because "oh what does that mean about me?" 
Emma shares how she had to get used to feeling this shame because as a "cis, hetero woman"

this was not a feeling that she was used to feeling but the process paid off:

That was my biggest barrier to acknowledging how I was reproducing heteronormative behavior, how I was reproducing racist ideologies and that stuff, like the shame that I experienced through the process of acknowledging that was really hard and really if I had been in another place and not had that support that I had I would have put walls up. When you have privilege, you don't feel ashamed of your identity and the opening of my eyes to how others were experiencing this reality was really, really hard and I think that is part of the conversation.

\section{Changes to ECE education and support}

This theme includes three suggestions from the participants that came up in the focus group discussion of how changes could be made in terms of ECE education and support in order to incorporate gender fluid discourses into practice. All of the participants were in definite agreement that changes to ECE preservice education and preservice support was needed.

\section{Changes to preservice education}

The participants agreed that it would be impactful and important to have gender fluid discourses and practices introduced in ECE preservice education. Dan brought up how important modeling is in preservice program:

If you go through a preservice program and no one asks what your pronoun is, you're not going to think about talking to kids about that or modeling that in your practice because it's not modeled for you at all, it isn't normalized, it isn't something that's embedded, right?

The other three participants agreed. Catherine shared a similar point:

If it's in our learning as Early Childhood Educators, then it's way more likely to be a normalized thing

Other suggestions to include in ECE preservice programs beyond modeling pronouns included practicing having difficult and uncomfortable conversations and also a suggestion from Emma: 
I firmly believe that in any education, like any education we receive as ECEs, actual physical strategies to become more self-aware need to be taught. Stop telling us to do it and tell us HOW to do it.

The other participants in the room voiced their agreement on Emma's contribution. Emma also suggested that ECEs be given chances to explore their identities in preservice courses in order to find out what your gender identity is and what that means to you.

\section{Workshops}

Catherine shared her disappointment in the many workshops she had attended, that there are a lack of meaningful workshops and that she felt as though she could teach any of the workshops being offered. Even when the workshop topic was interesting, Catherine found that it was not applicable to practice. She explained:

It's not realistic, they're not, we need workshops that have measurable things that we can take away. There needs to be specific tools, not a little handout, not a little flyer, specific tools and ways, ideas so that we can bring this forward to the rest of the crew.

Catherine suggested that workshops should instead be used as an "enhancement of your toolbox" and more substantial topics should be covered.

\section{Curriculum}

Dan suggested that a standardized curriculum on gender fluid discourses should be available for ECEs:

So that people can go to it and say like "okay I don't know how to talk about this but this, but this is where a guide that I can actually reference that will give me some sort of backing."

\section{Consultant}

Emma argued against this idea, relating it to working in traditional daycare and having to constantly make sure you are following all of the rules and the guidelines. She argued: 
My experience was this all of the time; "you are going to do this, you are going to do this, you are going to do this" and so, it was like all of this dictating around how I was going to behave, how I was going to like, it was so many things it was hard to remember all of the expectations of my behavior.

In contrast to this, Emma shared instead what motivated her:

The stuff that really motivated me was the stuff that I was collaborating with others on like I almost think it needs a lot of support, what if one of those people (of this team you put together - was talking about the team that drafted the standardized curriculum) goes in and each person goes to a different daycare and works with them in a collaborative way to be like for this context, for this space, how are we going to have these conversations?

Both Catherine and Dan chimed in with the same idea based on what Emma had shared - a

resource consultant. Emma continued on with the idea:

Yes, so it's like a consultant but then someone who's really going to like challenge that and that is also because that's my learning style which is why I advocate for that kind of stuff, I don't just learn by someone telling me stuff, I need to experience it, I need to talk about it. I need a relationship with the information. 


\section{CHAPTER 5. DISCUSSION}

The findings included many examples from the participants on how gender fluid discourses have been, and therefore could be, incorporated into ECEC practice. Materials that should be included in the classroom were the least frequent examples, whereas quite a few ideas on how to incorporate new or altered practices were discussed. What was less expected for this project was the time spent discussing how ECEs could be better supported in exploring alternative discourses, such as gender fluid discourses both in preservice education and once they had entered the field. Even more surprising was the discussions that took part around the image of the educator, mainly self-awareness and vulnerability.

My research question asked: How are Early Childhood Educators intentionally incorporating gender fluid discourses into their practice? In order to answer this question, I had hoped to uncover concrete examples and ideas of materials and practices that were not only already taking place in the field but, doing so successfully. I thought if I was able to speak with ECEs who believed that incorporating gender fluid discourses into their practice was important, I would have my answers. I would then have easily transferable examples that I could disseminate to other ECEs working in the field, in the hopes of bridging a gap between the conversations happening surrounding gender in academia and the lack of gender fluid practices happening in the field. Although I did find these examples, a few of materials and more of the rich ideas for practices that can be incorporated, I also found so much more. Instead of this project resulting in finding clean and easily transferable examples that would neatly answer my research question, my participants helped me understand that it was naïve to think that all the field needed was more examples, more lists, and more ideas. I now understand that the pervasiveness of developmental discourses can only be challenged with solutions that are just as extensive. It 
would take a major shift in thinking to result in fully integrated, meaningful, and purposeful incorporations of gender fluid discourses.

\section{Materials and Practices}

The previous discussion is not meant to belittle or take away from the ideas about materials and meaningful practices that were shared by my participants, as it was clear that they made up an important part of their ECEC practice. Kroeger, Recker, \& Gunn (2019) encourage educators to be mindful of the materials they select for their classrooms as they believe that "materials are among the most important aspects to consider when creating an inclusive, gender neutral classroom" (Reworking classroom materials section, para. 2). Gunn (2003), Gagliardi (2014), Sullivan (2016), and Farley (2017) all agree that incorporating a diverse representation of books in ECEC settings sends a powerful message and can be a useful tool (Kroeger, Recker \& Gunn, 2019). Participants also identified many valuable practices such as incorporating pronouns, reading critically, creating safe spaces, having important conversations, creating programs not based on the gender binary and using an embedded approach. Essential to note is the importance of the educator's actions and words as Cahill and Theilheimer (1999) assert. Indeed, this is what helps to "shape the classroom culture and tell children how teachers feel about gender barriers and gender exploration" (Kroeger, Recker \& Gunn, 2019, Acting and speaking inclusively section, para. 1).

These practices demonstrate that the participants have made sure to "acknowledge how gender limitations and biases might exist" (Reworking classroom materials section, para. 1) in their classroom settings and have actively worked to confront and reduce them (Kroeger, Recker \& Gunn, 2019; Freeman 2007; Sullivan 2016). The practices shared by the participants are not typical DAP practices in ECEC but rather represent the ECE's personal perspectives in what they 
believed was lacking in their programs or needed to be changed. These educators worked against the status quo in their centre and used trust and relationship building in order to alter their programs in ways that unsettle dominant discourses through critical thinking and alternative theories.

\section{Family Involvement}

Another prominent theme that emerged in the data was the benefit of family involvement. However, contrary to the popular argument that families often act as a barrier in incorporating gender fluid discourses in ECEC settings, the participants all felt that they had the support of their families in their program. That being said, this support was no coincidence, as the participants agreed that it was crucial to build strong relationships based on trust with the families in one's programs in order to be able to have difficult conversations and the freedom to implement alternative perspectives. Kroeger, Recker and Gunn (2019) agree that educators have the unique opportunity to encourage parents to incorporate gender fluid discourses and can act as an important resource for supporting the family. It is important to note that not only does building a relationship with the families in order to support incorporating gender fluid discourses shift gender discourses in the classroom, but also "encourages healthy development in all parts of a child's life" (Kroeger, Recker, \& Gunn, 2019, Fostering partnerships with families section, para. 2).

\section{Barriers to Implementation}

The two themes: the educator, and ECE education and support that are the findings that I find the most interesting to discuss. The reason for this is that in order to be able to incorporate the valuable materials and practices that were brought forth by my participants, and to do them any justice, the changes and challenges recommended by my participants need to be addressed 
first. If not, the risk of taking up a tokenistic or meaningless approach to incorporating gender fluid discourses is a likely consequence. Through the example of multicultural recognition (comparable to gender recognition) Nxumalo and Adair (2019) make clear that although recognition is important, it is not enough to truly shift the dominant discourses in ECEC settings and further action needs to be taken in order to incite true change.

\section{The Early Childhood Educator}

What was most interesting, as it was the most unexpected, was in the discussions surrounding the educator. Participants put a strong emphasis on self-awareness, vulnerability, and privilege. Emma's thoughts on the barriers ECEs face in engaging in vulnerable practice due to the fact that ECEs are responsible for everything that happens in the classroom and therefore are afraid to make mistakes can be tied to Silin's (2018) ideas. Silin (2018) speaks of the conservative nature of the field in which children must be protected from imaginary threats; it is in "echoing this protectiveness towards children" (p.61) that ECEs avoid thinking with alternative perspectives that may threaten dominant discourses and that perhaps also prevents them from engaging in reflective practice.

Participants also saw substantial value in the ECE's own personal journeys and life experiences, and some believed that ECEC cannot only be about the child. Silin (2018) believes in the "RECE commitment to a field where adults too might find pleasure and explore desire" (p.62), and when stuck within DAP frameworks, there is no room for educator agency in the classroom. Silin (2018) explains that it is desire itself that makes ECEs (as well as children) vulnerable, but that it is "a potential source of danger as well as pleasure, risk as well as reward" (p.62). The importance of ECE agency in the classroom is echoed by Nxumalo and Adair (2019) who share that it is with this agency that ECEs are able to better resist dominant discourses as a 
way to "address equity in the early schooling lives of young children" (p.668). It was

acknowledged by these authors that these were all difficult areas for ECEs to pursue, especially considering limited resources such as time and support, but when they did take part in these personal practices it made a valuable difference in their practice and in their classrooms.

When ECEs self-reflect, acknowledge their privilege, and think critically they are challenging the dominant discourses of the image of the educator. Within developmentalism, ECEs are positioned as the all-knowing, expert, implying "that the educator knows what children need; it also suggests knowledge or power" (Pacini-Ketchabaw, et al., 2015, p.63). Although this may feel like a safe space for an educator to operate, it discourages self-reflection, critical thought and limits their abilities to think with new perspectives (Pacini-Ketchabaw, et al., 2015). Thus, in partaking in these new ways of thinking and practice, this long-standing image of the educator is challenged, but again this may be difficult for ECEs to engage in without adequate support. Pacini-Ketchabaw et al. (2015) encourage breaking down these limiting images of the educator and encourage reconceptualizing the educator. Alternative images of the educator requires reconceptualizing professional development and instead viewing the ECE "as an incomplete project, as unfinished" (Britzman, 2007, p.3).

\section{Changes to ECE education and support}

It is important that these sections coexist as it was discussed in the literature review, Warin \& Adriany (2017) found that training on its own is not enough for ECEs to be able to demonstrate meaningful gender fluid discourses in their practice. ECEs must also be able to think consciously, be able to practice thinking and reflecting critically, be able to identify pervasive gender norms and hold awareness and understandings of their own personal belief systems in order to help create true change (Warin \& Adriany, 2017). The section above 
illustrates how the participants in this study were clear on what they believed would support incorporating gender fluid discourses into practice, they were also clear on what they thought would help make this a reality. The participants recommended changes to preservice education, offering quality workshops, adding to the curriculum, and developing a consultant role. The overarching similarity between what the participants offered as suggestions is that ECEs want, need and are lacking the support required to incorporate gender fluid discourses into their ECEC practice.

The need to incorporate self-reflection, or reflective practice, into ECEC is not a new idea. In fact, the Ontario College of Early Childhood Educators (CECE) promotes and encourages reflective practice and self-directed learning as part of their Continued Professional Learning (CPL) program (2017). The Ontario government document How Does Learning Happen? (2014) includes an entire section on the educator, and the section includes discussion of both critical reflection and collaborative inquiry. Although, not focused on self-reflection in regard to gender fluid discourses, these documents include similar information to what my participants were seeking. For example, CPL (2017) encourages critical reflection "that requires RECs to consider and challenge their beliefs, assumptions, and understandings that frame how they view and respond to children and that shape learning experiences [collaborative inquiry that encourages RECEs to] engage with others in critical reflection" (p.2) and to practice selfreflection. Nevertheless, there is no direct mention of gender in these documents (MacNevin \& Berman, 2017) and not surprisingly according to the responses of my participants, it seems as though the documents are not sufficient.

If CPL (2017) and How Does Learning Happen? (2014) are encouraging similar ideas and offering materials for ECEs to follow in regard to other areas of interest in ECEC, then why 
did my participants not mention these resources and instead offer their own ideas of possible resources? Although reflective practice has been encouraged for some time and is known as "a hallmark of quality teachers" and as "the bedrock of their professional growth" (Mac Naughton, 2005, p.5), the omnipresent influence of developmental theory in ECEC settings (as demonstrated in the literature review) might be limiting the possibilities of reflective practice in ECEC. Pacini-Ketchabaw et al. (2015) call for complete "reconceptualizing professional development" (p.67) and hope to "turn the idea of professional development on its head" (p.67). Could it be that knowledge of alternative discourses and ways of doing things are essential in order for reflective practice to be conducted in a way that will challenge and move the field in new directions?

It was my intention to hear from knowledgeable ECEs in order to hear how they have successfully incorporated gender fluid discourses into their practices and, therefore, the recommendations shared by the ECEs in this study are important to consider. The desire and the need for support in incorporating new discourses is made clear. Changes to preservice education would ensure that gender fluid ideas are presented, practiced and modeled for ECEs in the time they have before they enter the field, making it more likely that they will be incorporated into practice. Offering meaningful workshop options was suggested, but in an article that offers suggestions on how to incorporate anti-racist curricula into practice (Berman, Daniel, Butler, MacNevin, \& Royer, 2017), the authors note that "additive approaches" such as a one-off workshop "fails to expose, disrupt, or challenge, the entrenched White-European curriculum" (p.61). I would argue that anti-racist curriculum is similar enough to approaches that incorporate gender fluid discourses and, therefore, it is safe to say that a few one-off workshops would unlikely be enough to shift practice. That being said, it is crucial that the professors and 
instructors in preservice education understand gender fluid discourses and their importance, otherwise the learning of preservice students will suffer as a result (Berman et al., 2017). A curriculum well-versed in gender fluid practices and ideas from Queer theory will ensure that ECEs will have information that can continue to support them in their practice, and ultimately support the children with whom they work.

The participants also suggested incorporating a consultant that could become part of the centre for the time being in order to support collaboration and integration of gender fluid discourses, which would be especially important for those already in the field. This suggestion is compelling as it seems to address a few of the concerns while utilizing already discussed shifts in professional development methods as Pacini-Ketchabaw et al. (2015) suggest. Similar to a resource consultant, but instead of only providing support and experience with children with additional support needs, they would provide experience and support in challenging dominant discourses, in this case discourses that are specific to gender. Such a resource consultant would support ECE learning through collaboration, which fits with the suggestions by How Does Learning Happen (Government of Ontario, 2014), in CPL (CECE, 2017) and from Emma. This is similar to the idea of a pedagogista in a Reggio Emilia pedagogical approach, as this is "someone who contributes pedagogically to educational projects; the exact work is profoundly contextual" (Vintimilla, 2018, p.21). Perhaps a pedagogista would encourage and support the challenging thinking required to make known and disrupt the dominant gender discourses that my participants were seeking and suggesting as helpful.

This section of discussion may seem to conclude without any significant 'answers', this is due to the complex nature of ECEC and the dire need to reconceptualize it. Perhaps it is as Pacini-Ketchabaw et al. (2015) suggest, instead of emphasizing "changing the educator and their 
practices by implementing a specific sort of change, such as a program [the image of professional development needs to shift from] being to becoming [allowing for] dissonance, plurality, change, transience, and disparity" (p.67). In the end, encouraging the educator to not only be a teacher, but a learner, appreciate both answers and questions, to welcome alternative perspectives and see them as opportunities for conversation (Pacini-Ketchabaw et al., 2015).

\section{Strengths and Limitations}

\section{Validity}

Qualitative research should not be measured by the same markers of quality that are used to assess quantitative research. According to Tracy (2010), "high quality qualitative methodological research is marked by (a) worthy topic, (b) rich rigor, (c) sincerity, (d) credibility, (e) resonance, (f) significant contribution, (g) ethics, and (h) meaningful coherence" (p.839). In this section I will be discussing (a) worthy topic, (c) sincerity, and (g) ethics.

\section{Worthy topic}

As previously discussed, this research is relevant, timely, significant and interesting, thus meeting the criteria of being a worthy topic according to the "Big-Tent" criteria (Tracy, 2010). In today's political climate, challenging developmental theory and working to incorporate alternative perspectives is an urgent issue. The taken for granted assumptions of DAP can no longer support (or possibly never could) the intricate social worlds of children and families today. It is crucial that gender fluid discourses be understood and practiced by ECEs in ECEC settings in order to support the gender exploration of all children for the many reasons already outlined in this paper. 


\section{Sincerity}

Tracy (2010) describes sincerity as "an end goal [that] can be achieved through selfreflection, vulnerability, honesty, transparency, and data auditing" (p.841). Reflexivity has been demonstrated throughout this paper, as I have sought to take the time to consider my beliefs and arguments and to make them known to the reader (Tracy, 2010). I began this project knowing that it was the right time to take it on as I had prepared for the MRP with two successful terms of graduate courses and, I had the opportunity to work with the supervisor (Dr. Rachel Berman) I had chosen because I thought she would be a good fit and would be able to provide me with the support I needed. As the project continued, I was able to seek feedback from my first participant as her interview was used to prepare for the focus group session. I was honest in explaining how my results differed from what I was expecting and discussed my findings with my supervisor to ensure I was on the right track. Tracy (2010) describes sincere researchers as "approachable rather than self-important and friendly rather than snobbish" (p.842). It has been my goal throughout this project to be accessible and honest and I believe that I have been successful in this.

\section{Ethical}

Tracy (2010) describes procedural ethics as encompassing "the importance of accuracy and avoiding fabrication, fraud, omission, and contrivance" (p.847) and I have sought to ensure that this project be ethical from the very drafting of the project, to its finish and beyond. This project was submitted to and approved by the Ryerson Ethics Board (REB) before beginning any research. I ensured that my research participants were aware of any potential risks and benefits associated with this study, understood that their participation in the study was voluntary and that they were welcome to withdraw their participation at any point. This was explained to them 
through the consent form and during the introduction of the focus group. Beyond this, I have sought to honour my participants' perspectives in my presentation and discussion of my findings.

\section{Limitations of the Research}

Using a purposeful sample was ideal for answering my research question but the four participants who took part in the focus group session are not representative of all ECEs. It would also be beneficial to hear what other ECEs have to say about gender in ECEC settings. Again, due to my purposeful sample I was fortunate to have very experienced participants who were eager to share and therefore there was no issue with participation during the session. As a novice researcher, this made it difficult for me to interrupt the conversation at times and some questions were missed. That being said, the focus group did stay on topic and I value the direction that the focus group went organically, but time may have been used more wisely at some points and more questions might have been covered.

Including more participants and more focus group sessions would have resulted in more data. More data may have further confirmed the findings of this study or introduced new concepts and ideas that were not brought forth by my participants. Though rich, the findings of this research are likely not an exhaustive list of all the ways gender fluid discourses can be incorporated into practice and how ECE practice and support could be improved, however, there likely is no such thing as an exhaustive list. The findings reflect the gender fluid practices that have been successful for a small number of participants in their practice and may potentially be of use for others in the field. It is important to also note that because I used my research question to code the data, it is possible that I may have missed other information that was shared by my participants. 


\section{Future Research}

This research helps to demonstrate what knowledge a small number of ECEs are using in their ECEC practice, and more specifically how they have incorporated gender fluid discourses into their practice. One of the goals of this research was to work towards filling a gap between the academic conversations happening surrounding gender in ECEC settings and what may be occurring in practice. In order to continue trying to fill this gap, it would be beneficial to continue talking to ECEs in order to have their voices represented in research, as they are the experts in their field and can speak to what is happening on the front line. Hearing ECEs discuss what sort of alternative discourses they are incorporating into practice, how and if they are working, why or why not, and what can be done may help continue moving towards reconceptualizing the field of ECEC in a way that is accessible to those who it impacts, children and ECEs. Although this paper may not be accessible to children, it is also important that future research continues to be done with children and by children and that is also accessible to children as they too are the experts of their own lives.

\section{Conclusion}

Starting with an exploration of how dominant discourses operate and control discourses in ECEC settings, this study explored how gender fluid discourses are being incorporated into ECEC settings. By speaking with ECEs who are currently practicing or have practiced in the past, participants not only shared their ideas on materials and practices they had incorporated but also their thoughts on the educator and changes that they believe need to be made to ECE preservice education and support. Important to note is the fact that the rich and meaningful ideas shared by the participants in this project are the working ideas of ECEs who have taken both the time and the risk to practice self-awareness, self-reflection and have made a point to make this a 
part of their project. Again, echoing the idea that these practices of self are imperative to truly incorporating gender fluid practices into ECEC settings and beyond. With NAEYC beginning to demonstrate their readiness to discuss alternative ways to approach gender in ECEC settings, along with the compelling thoughts and ideas presented here, shared by passionate ECEs who are already practicing meaningful gender fluid discourses in their practice testifies that there is hope for the future of ECEC. Perhaps a future consisting of reconceptualized ECEC and gender fluid discourses is closer than was originally thought. 


\section{APPENDIX A \\ Glossary of Terms}

\section{Gender fluid:}

The definition of gender fluid for the sake of this project and that was shared with the participants during the introduction of their interviews is as follows: Instead of understanding gender as a binary (boy/girl) gender can be understood as a spectrum that individuals can navigate freely.

\section{Gender:}

Not to be mistaken with the sex of the physical body. Gender is a social construct, often influenced through social norms and expectations. Ehrensaft explains that although gender is not something an individual is born with, biology may still be considered, it is a complex “interweaving of nature, nurture and culture” (Ehrensaft, 2016, p. 15).

\section{Gender binary:}

The gender binary is a system made of the limiting belief that there are only two gender categories that are both separate and opposite of each other. These two categories (Man / Woman or Boy / Girl) are made up of a set of norms and expectations that are expected to be followed.

\section{Gender spectrum:}

Alternatively, gender spectrum is a system of the belief that an individual has the freedom to identify and express their gender as they see fit. Rather than remaining bound by predefined norms and expectations such as within the binary, the spectrum is fluid and leaves room for infinite gender outcomes.

\section{Heteronormative:}


Heteronormative refers to the normalization of heterosexual ideals in Western society. Including, but not limited to ideas of monogamy, heterosexual relationships, normative family roles, and binary gender roles.

\section{Cisgender:}

A cisgender individual is an individual whose biological sex is aligned with their gender identity

\section{LGBTQ2SA+:}

A term used to represent "non-heterosexual and/or non-cisgender individuals, topics and communities" that (“What Does LGBT2Q+ Mean?”, n.d.) translates to: L - lesbian, G - gay, B -

Bisexual, $\mathrm{T}$ - transgender, $\mathrm{Q}$ - queer/questioning, $2 \mathrm{~S}$ - two spirit, $\mathrm{A}$ - asexual, + - used to represent that there are more sexual orientations and gender expressions.

\section{Pronoun:}

Pronouns include She/Her/Hers, They/Them, Him/He/His, or any combination of the three. Pronouns are not based on the appearance of an individual and are to be self-identified by the individual.

\section{ECEC:}

ECEC is the early childhood education and care sector, it encompasses early learning and child care settings such as licensed child care, home child care, and full day kindergarten programs in Ontario (Mohamed, 2019).

\section{DAP:}

A framework developed by NAEYC that is grounded "both in the research on child development and learning and in knowledge about educational effectiveness and promotes young children's optimal learning and development” ("Developmentally Appropriate Pracitce," n.d., para 1). 


\section{$\begin{array}{ll}\text { Research } \\ \text { Ryerson } & \text { Ethics Board }\end{array}$}

To: Chloe Waters

Early Childhood Studies

Re: REB 2019-179: Gender Fluid Discourses: How can they be incorporated into early childhood settings?

Date: May 22, 2019

Dear Chloe Waters,

The review of your protocol REB File REB 2019-179 is now complete. The project has been approved for a one year period. Please note that before proceeding with your project, compliance with other required University approvals/certifications, institutional requirements, or governmental authorizations may be required.

This approval may be extended after one year upon request. Please be advised that if the project is not renewed, approval will expire and no more research involving humans may take place. If this is a funded project, access to research funds may also be affected.

Please note that REB approval policies require that you adhere strictly to the protocol as last reviewed by the REB and that any modifications must be approved by the Board before they can be implemented. Adverse or unexpected events must be reported to the REB as soon as possible with an indication from the Principal Investigator as to how, in the view of the Principal Investigator, these events affect the continuation of the protocol.

Finally, if research subjects are in the care of a health facility, at a school, or other institution or community organization, it is the responsibility of the Principal Investigator to ensure that the ethical guidelines and approvals of those facilities or institutions are obtained and filed with the REB prior to the initiation of any research.

Please quote your REB file number (REB 2019-179) on future correspondence.

Congratulations and best of luck in conducting your research.

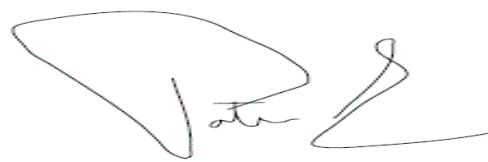

Dr. Patrizia Albanese, $\mathrm{PhD}$

Chair, Ryerson University Research Ethics Board

The Following protocol attachments have been reviewed and approved. 
APPENDIX C

Recruitment Flyer

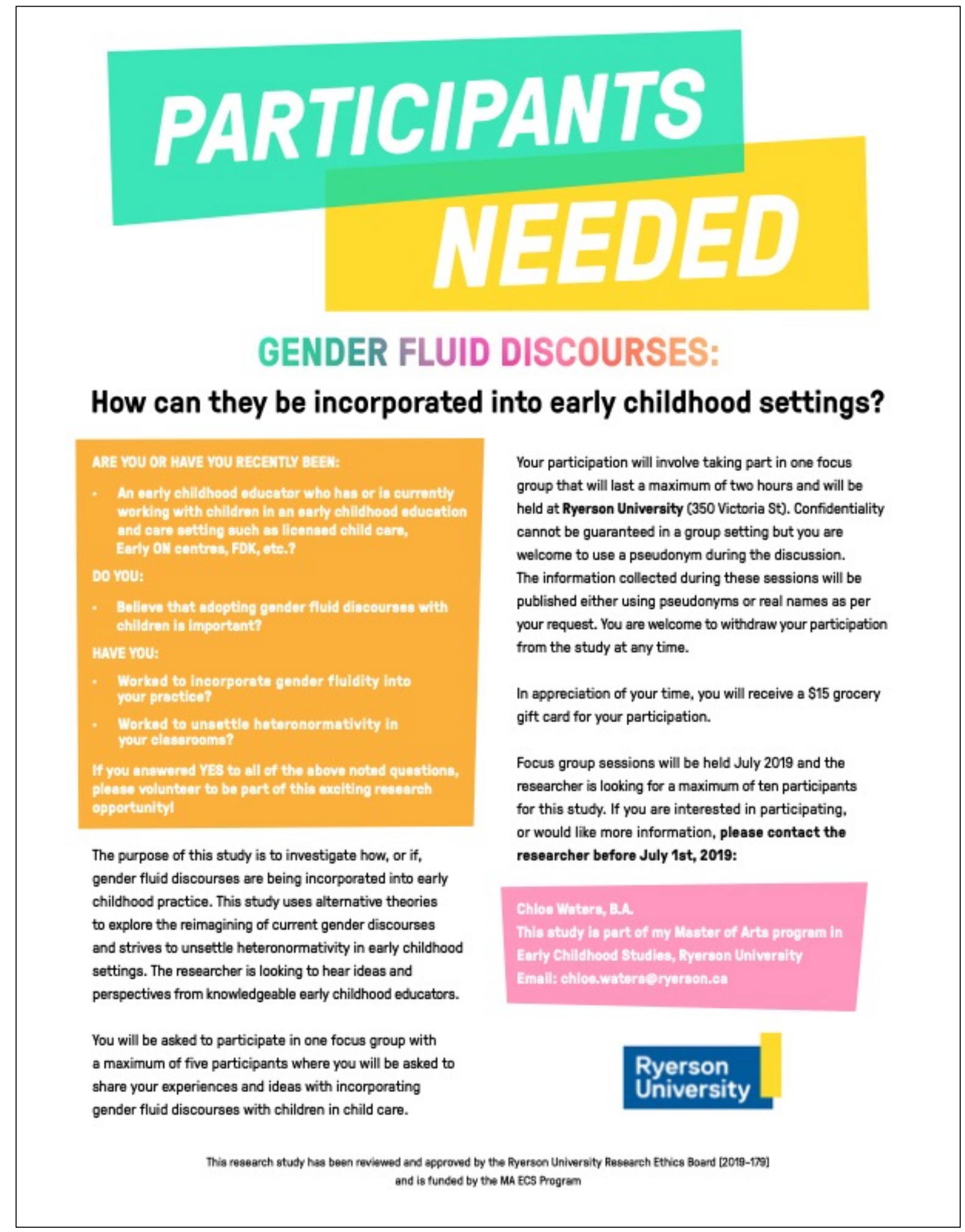


APPENDIX D

Consent Form A

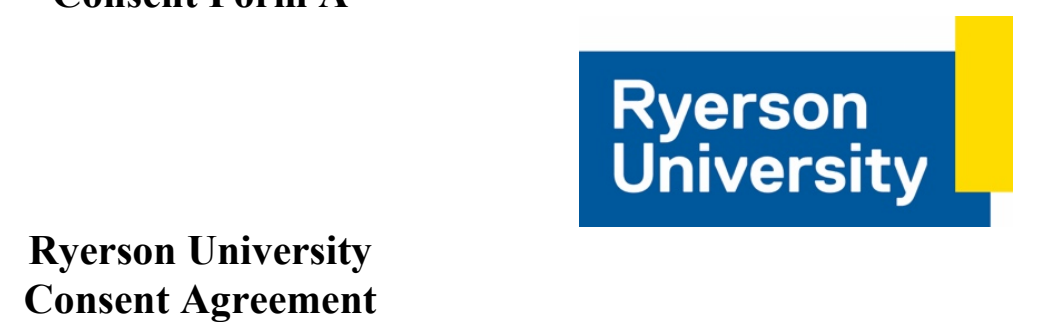

You are being invited to participate in a research study. Please read this consent form so that you understand what your participation will involve. Before you consent to participate, please ask any questions to be sure you understand what your participation will involve.

\section{Gender Fluid Discourses: \\ How can they be incorporated into early childhood settings?}

Phone interview consent agreement

\section{INVESTIGATORS:}

This research study is being conducted by Chloe Waters B.A. and is being supervised by Dr. Rachel Berman, from the Early Childhood Studies MA program at Ryerson University. This study is being conducted as part of the investigator's graduate studies for the partial completion of their Master's degree.

This study is funded by the Early Childhood Studies MA program at Ryerson University.

If you have any questions or concerns about the research, please feel free to contact either Chloe Waters or Dr. Rachel Berman:

\section{Chloe Waters}

Investigator: chloe.waters@ryerson.ca

Dr. Rachel Berman

Supervisor: rcberman@ryerson.ca, 416-979-5000, press 1 x.7695

\section{PURPOSE OF THE STUDY:}

The purpose of this study is to investigate how gender fluid discourses can be incorporated into early childhood practice. This study uses alternative theories to explore the reimagining of current gender discourse and strives to unsettle heteronormativity in early childhood settings. The investigator is looking to hear ideas and perspectives from knowledgeable early childhood educators. 
In order to participate in this study, you must currently (or recently) be working in the field of early childhood education and care, and have experience working with children in a childcare setting. You must believe that adopting a gender fluid discourse is important and you believe that you have made this a part of your practice.

There will be a maximum of ten participants recruited for this study with a maximum of five participants per focus group session. The results of this study will contribute to a graduate major research project, possibly be published and presented at conferences and workshops.

\section{WHAT PARTICIPATION MEANS:}

If you volunteer to participate in this study, you will be asked to do the following things:

- Participate in one phone interview. This phone interview will last a maximum of 40 minutes.

- The phone interview will include questions on why gender fluid discourses are important and how they can be incorporated into practice. The interview questions will be emailed to you beforehand.

- The aim of the phone interview is to have a discussion that may help inform an upcoming focus group session. You are not required to answer any question that you are not comfortable with.

- There is a demographic from at the end of this consent form with questions regarding your work experience. Participant emails will also be collected in order to contact the participants. Sharing your real name in any published materials is not required.

- Research findings will be available to participants and will be distributed to participants by email no later than October 2019.

\section{POTENTIAL BENEFITS:}

There may be general benefits from this research study, but it is likely that there may be none. The purposeful selection of participants in this study will ensure that adopting gender fluid discourses will be important to all participants. Therefore, the phone will be an opportunity to share information regarding gender fluid discourses in the early childhood education field.

Potential benefits include the results of this study being used to share information on gender fluid discourses, which may help shift the gender narrative in ECE practice. The information from this study will contribute to the existing research and conversations on gender fluidity in ECE.

The investigator cannot guarantee, however, that you will receive any benefits from participating in this study. 


\section{THE POTENTIAL RISKS TO YOU AS A PARTICIPANT:}

The potential risks for participating in this study are low. You are not required to discuss or answer anything that you are not comfortable with and may stop your participation either temporarily or permanently at any point. The minimal risks may include:

\section{Psychological risk}

- Feeling uncomfortable and/or upset

\section{How will this be managed?}

- Participants have the right to withdraw from the study at any point

- Contact information for LGBTQ2SIA+ friendly therapists can be found attached to this consent form

- This consent form will be sent to participants by email for their review prior to the phone interview when possible

\section{Social risk}

- Risk of being exposed

- Public embarrassment

- Damage to participants reputation as an educator

\section{How will this be managed?}

- Pseudonyms will be used in the written study and workplaces will not be shared or recorded in transcription

- Confidentiality is guaranteed and names will not be shared without permission to do so

Discussions surrounding gender may be controversial or uncomfortable for some. It is possible that some participants may have had negative experiences surrounding gender and the focus group discussions may bring up some of these memories. No real names or identifiers will be shared in any publications or presentations without permission. A list of services and supports are listed at the end of this form in case any of these negative experiences arise and you feel that you would like to seek professional help.

\section{CONFIDENTIALITY:}

Due to the nature of a one on one interview, confidentiality is guaranteed. Once the information from the phone interview is collected, a pseudonym will be given to participants and the data that will be shared will be anonymous to the readers. If you would prefer that your real name is used in published material, you may indicate this on the signatory page at the end.

The phone call interview will be audio-recorded, and the investigator will be taking notes during the session.

\section{DUTY TO REPORT:}


If information is shared that would require the researcher to report to legal authorities, such as instances of child abuse or other harmful or illegal instances, it is the researcher's legal duty to do so.

\section{DATA STORAGE:}

The audio recordings that are collected during the phone interview will be stored securely and will be kept locked and secured on the researcher's Ryerson University Google drive with two-factor-authentication. The audio recordings will be deleted immediately upon transcription and verification.

The written notes will be immediately typed up onto a word document that will also be stored securely and will be kept locked and secured on the investigator's Ryerson University Google drive with two-factor-authentication. The written copy of the notes will be shredded immediately upon completion.

The signed consent forms will be kept locked in a secure location. Only the investigator and her supervisor will have access to these materials.

This information will not be released to any other party for any other reason.

These materials will be held for one year and will be destroyed September 2020. All traces of data that is saved on the investigator's Ryerson University Google drive will be deleted. All hard copy materials that have been locked in a secure location will be shredded and securely disposed of.

\section{DATA DISSEMINATION:}

The results of this study will contribute to a graduate major research project. It is possible that the data collected in this study will be shared through conference presentations and workshops. It is possible that the data collected in this study will be published in a journal or a book.

Participants will have access to the final results of the study and any future published materials if requested.

If participants are interested in accessing the research of other students at Ryerson University, they may follow this link:

https://digital.library.ryerson.ca

\section{INCENTIVES FOR PARTICIPATION:}

Participants will be given a fifteen-dollar (\$15) grocery gift card as a thank you for participating in the phone interview. If at any time you choose to end your participation in the study, you will still receive the gift card. 


\title{
COSTS TO PARTICIPATION:
}

There are no direct costs associated with participating in the study.

\section{VOLUNTARY PARTICIPATION AND WITHDRAWAL:}

Your participation in this study is completely voluntary, it is up to you if you would like to be in this study or not. If any question makes you uncomfortable, you can choose to skip that question. You may stop participating at any time and you will still be given the gift card. If you chose to withdraw from the study at any point, the information you have shared will not be included in the project without your permission. If you decide that you do not want any of the information you have shared in the phone interview to be included in the study, you must let the investigator know by July $26^{\text {th }}, 2019$ and the information you have shared will not be included and will be deleted. Your choice of whether or not to participate will not influence your future relations with Ryerson University, the investigator (Chloe Waters) or her supervisor (Dr. Rachel Berman).

\section{QUESTIONS ABOUT THE STUDY:}

If you have any questions about the research now, please ask. If you have questions later about the research, you may contact:

\section{Chloe Waters}

Investigator: chloe.waters@ryerson.ca

\section{Dr. Rachel Berman}

Supervisor: rcberman@ryerson.ca, 416-979-5000, press 1, x. 7695

This study has been reviewed by the Ryerson University Research Ethics Board (REB 2019 179). If you have questions regarding your rights as a participant in this study, please contact:

\author{
Research Ethics Board \\ c/o Office of the Vice President, Research and Innovation \\ Ryerson University \\ 350 Victoria Street \\ Toronto, ON M5B 2K3 \\ 416-979-5042 \\ rebchair@ryerson.ca \\ Gender Fluid Discourses: \\ How can they be incorporated into early childhood settings?
}

Early Childhood Educator consent agreement

\section{CONFIRMATION OF AGREEMENT:}


Your signature below indicates that you have read the information in this agreement and have had a chance to ask any questions you have about the study. Your signature also indicates that you agree to participate in the study and have been told that you can change your mind and withdraw your consent to participate at any time. You have been given a copy of this agreement.

You have been told that by signing this consent agreement you are not giving up any of your legal rights.

Name of Participant (please print)

Signature of Participant

Date

The phone interview session will be audio-recorded for documentation purposes. This audio recording will be securely stored on the researcher's Ryerson University Google drive with two-factor-authentication until it has been transcribed. Once transcribed onto a word document and verified, all traces of the audio recordings will be deleted. The transcription of the audio recordings will be securely stored on the researcher's Ryerson University Google drive with two-factor-authentication.

I agree to be audio-recorded for the purposes of this study. I understand how these recordings will be stored and destroyed.

Signature of Participant

Date

Gender Fluid Discourses:

How can they be incorporated into early childhood settings?

NAME: 
In the published document, I would like to use:

I would like to be emailed a copy of:

\section{LIST OF SERVICES AND SUPPORTS}

1. Umbrella Mental Health Network - 691 Bloor St West, Suite 202

We offer psychology and psychotherapy services to individuals, couples, and families in the $L G B T Q+$ community, ranging from those queer spawn to people who identify with broader lenses of queerness

PH: 647-687-6543

EMAIL: info@umhn.ca

WEBSITE: https://www.umhn.ca

2. Dr. Nicola Brown -195 College St, $3^{\text {rd }}$ floor 
If you are an individual adult looking for psychotherapy in downtown Toronto, I may be able to help. I am experienced working with: anxiety, depression, trauma, family and relationship issues, loss and grief, self-esteem and assertiveness, workplace stress, sexuality, gender identity/transition planning. My practice is gay, lesbian, bi and trans positive

WEBSITE: http://www.nicolabrown.ca/index.htm

PH: 647-501-2045

EMAIL: nicola@nicolabrown.ca

\section{Psychotherapy Referral Service}

PRS connects you with a registered psychotherapist in Toronto or the GTA. You won't have to look further to get matched up with a Toronto therapist that will use effective and professional approaches to help you. Whether you are open to getting matched to a therapist or want to select them with your preferences in mind, PRS will get you connected to a qualified therapist.

WEBSITE: https://prstoronto.com 


\section{APPENDIX E}

\section{Consent Form B}

\section{Ryerson University}

\section{Ryerson University Consent Agreement}

You are being invited to participate in a research study. Please read this consent form so that you understand what your participation will involve. Before you consent to participate, please ask any questions to be sure you understand what your participation will involve.

Gender Fluid Discourses:

How can they be incorporated into early childhood settings?

Early Childhood Educator consent agreement

\section{INVESTIGATORS:}

This research study is being conducted by Chloe Waters B.A. and is being supervised by Dr. Rachel Berman, from the Early Childhood Studies MA program at Ryerson University. This study is being conducted as part of the investigator's graduate studies for the partial completion of their Master's degree.

This study is funded by the Early Childhood Studies MA program at Ryerson University.

If you have any questions or concerns about the research, please feel free to contact either Chloe Waters or Dr. Rachel Berman:

\section{Chloe Waters}

Investigator: chloe.waters@ryerson.ca

Dr. Rachel Berman

Supervisor: rcberman@ryerson.ca, 416-979-5000, press 1 x. 7695

\section{PURPOSE OF THE STUDY:}

The purpose of this study is to investigate how gender fluid discourses can be incorporated into early childhood practice. This study uses alternative theories to explore the reimagining of current gender discourse and strives to unsettle heteronormativity in early childhood settings. The investigator is looking to hear ideas and perspectives from knowledgeable early childhood educators.

In order to participate in this study, you must currently (or recently) be working in the field of early childhood education and care, and have experience working with children in a childcare 
setting. You must believe that adopting a gender fluid discourse is important and you believe that you have made this a part of your practice.

There will be a maximum of ten participants recruited for this study with a maximum of five participants per focus group session. The results of this study will contribute to a graduate major research project, possibly be published and presented at conferences and workshops.

\section{WHAT PARTICIPATION MEANS:}

If you volunteer to participate in this study, you will be asked to do the following things:

- Participate in one focus group session with a maximum of four other participants being held at Ryerson University (350 Victoria St). This focus group session will last a maximum of two hours.

- The focus group discussion will include questions on why gender fluid discourses are important to you and how you are incorporating gender fluidity into your practice.

- The aim of the focus group session is to encourage a rich discussion and sharing of ideas. You are not required to participate or share in any part of the discussion that you are not comfortable with.

- There is a demographic from at the end of this consent form with questions regarding your work experience. Participant emails will also be collected in order to contact the participants. Sharing your real name or name of your workplaces during the focus group session or in any published materials are not required.

- Research findings will be available to participants and will be distributed to participants by email no later than October 2019.

\section{POTENTIAL BENEFITS:}

There may be general benefits from this research study, but it is likely that there may be none. The purposeful selection of participants in this study will ensure that adopting gender fluid discourses will be important to all participants. Therefore, the sharing of ideas in the focus group session will be an opportunity to listen to and share information regarding gender fluid discourses in the early childhood education field. Potential benefits include the results of this study being used to share information on gender fluid discourses, which may help shift the gender narrative in ECE practice. The information from this study will contribute to the existing research and conversations on gender fluidity in ECE.

The investigator cannot guarantee, however, that you will receive any benefits from participating in this study. 


\section{THE POTENTIAL RISKS TO YOU AS A PARTICIPANT:}

The potential risks for participating in this study are low. You are not required to discuss or answer anything that you are not comfortable with and may stop your participation either temporarily or permanently at any point. The minimal risks may include:

\section{Psychological risk}

- Feeling uncomfortable and/or upset

\section{How will this be managed?}

- Participants have the right to withdraw from the study at any point

- Contact information for LGBTQ2SIA+ friendly therapists can be found attached to this consent form

- This consent form will be sent to participants by email for their review prior to attending the focus group when possible

\section{Social risk}

- Risk of being exposed

- Public embarrassment

- Damage to participants reputation as an educator

\section{How will this be managed?}

- The researcher will keep the focus groups as confidential as possible

- Pseudonyms will be used in the written study and workplaces will not be shared or recorded in transcription

- Confidentiality cannot be fully guaranteed as this will be a group discussion, but participants will be reminded to keep the information that is shared confidential

- Due to the purposeful sample of educators who have identified that gender fluid discourses are important to them, participants of this focus group are unlikely to experience this social risk within the context of the group

- Participants will be encouraged to not share their real names in the focus groups if they are concerned about their identities being exposed

\section{Personal identity being revealed}

- Focus groups cannot be kept fully confidential as the participants will be interacting with each other in a group discussion

- There is a risk that other participants may share the personal identities of others

\section{How will this be managed?}

- Participants will be reminded that the conversations and identities of those participating in the focus group should be kept confidential

- Participants will be encouraged to not share their real names or workplaces if they are concerned about their identity being exposed 
- The researcher will ensure that the focus groups are kept anonymous when being put into writing. Pseudonyms will be used in the study unless the participant requests that their real names be used. If workplaces are used, they will be anonymized by the researcher

Discussions surrounding gender may be controversial or uncomfortable for some. It is possible that some participants may have had negative experiences surrounding gender and the focus group discussions may bring up some of these memories. The investigator cannot guarantee confidentiality in a group discussion but if you are concerned about your identity being exposed, you are welcome to give a pseudonym at the focus group. No real names or identifiers will be shared in any publications or presentations without permission. A list of services and supports are listed at the end of this form in case any of these negative experiences arise and you feel that you would like to seek professional help.

\section{CONFIDENTIALITY:}

The participation in focus groups requires group interaction and discussion and for that reason confidentiality cannot be guaranteed. You are not required to share your name during the focus group and if you have concerns over being identified, you are welcome to use a pseudonym during the discussion. Once the information from the focus groups is collected, pseudonyms will be given to all participants and the data that will be shared will be anonymous to the readers. If you would prefer that your real name is used in published material, you may indicate this on the signatory page at the end.

The focus group session will be audio-recorded, and the investigator will be taking notes during the session.

\section{DUTY TO REPORT:}

If information is shared that would require the researcher to report to legal authorities, such as instances of child abuse or other harmful or illegal instances, it is the researcher's legal duty to do so.

\section{DATA STORAGE:}

The audio recordings that are collected during the focus groups will be stored securely and will be kept locked and secured on the researcher's Ryerson University Google drive with two-factor-authentication. The audio recordings will be deleted immediately upon transcription and verification.

The written notes will be immediately typed up onto a word document that will also be stored securely and will be kept locked and secured on the investigator's Ryerson University Google drive with two-factor-authentication. The written copy of the notes will be shredded immediately upon completion. 
The signed consent forms will be kept locked in a secure location. Only the investigator and her supervisor will have access to these materials.

This information will not be released to any other party for any other reason.

These materials will be held for one year and will be destroyed September 2020. All traces of data that is saved on the investigator's Ryerson University Google drive will be deleted. All hard copy materials that have been locked in a secure location will be shredded and securely disposed of.

\section{DATA DISSEMINATION:}

The results of this study will contribute to a graduate major research project. It is possible that the data collected in this study will be shared through conference presentations and workshops. It is possible that the data collected in this study will be published in a journal or a book.

Participants will have access to the final results of the study and any future published materials if requested.

If participants are interested in accessing the research of other students at Ryerson University, they may follow this link:

https://digital.library.ryerson.ca

\section{INCENTIVES FOR PARTICIPATION:}

Participants will be given a fifteen-dollar (\$15) grocery gift card as a thank you for participating in the focus group. If at any time you choose to end your participation in the study, you will still receive the gift card.

\section{COSTS TO PARTICIPATION:}

There are no direct costs associated with participating in the study. Participants will be responsible for getting themselves to Ryerson University (350 Victoria $\mathrm{St}$ ) for one focus group session.

\section{VOLUNTARY PARTICIPATION AND WITHDRAWAL:}

Your participation in this study is completely voluntary, it is up to you if you would like to be in this study or not. If any question makes you uncomfortable, you can choose to skip that question. You may stop participating at any time and you will still be given the gift card. If you chose to withdraw from the study at any point, the information you have shared will not be included in the project without your permission. If you decide that you do not want any of the information you have shared in the focus group to be included in the study, you must let the investigator know by 
July $26^{\text {th }}, 2019$ and the information you have shared will not be included and will be deleted. Your choice of whether or not to participate will not influence your future relations with Ryerson University, the investigator (Chloe Waters) or her supervisor (Dr. Rachel Berman).

\title{
QUESTIONS ABOUT THE STUDY:
}

If you have any questions about the research now, please ask. If you have questions later about the research, you may contact:

\section{Chloe Waters}

Investigator: chloe.waters@ryerson.ca

Dr. Rachel Berman

Supervisor: rcberman@ryerson.ca, 416-979-5000, press 1, x. 7695

This study has been reviewed by the Ryerson University Research Ethics Board (REB 2019 179). If you have questions regarding your rights as a participant in this study, please contact:

\author{
Research Ethics Board \\ c/o Office of the Vice President, Research and Innovation \\ Ryerson University \\ 350 Victoria Street \\ Toronto, ON M5B 2K3 \\ 416-979-5042 \\ rebchair@ryerson.ca \\ Gender Fluid Discourses: \\ How can they be incorporated into early childhood settings?
}

Early Childhood Educator consent agreement

\section{CONFIRMATION OF AGREEMENT:}

Your signature below indicates that you have read the information in this agreement and have had a chance to ask any questions you have about the study. Your signature also indicates that you agree to participate in the study and have been told that you can change your mind and withdraw your consent to participate at any time. You have been given a copy of this agreement.

You have been told that by signing this consent agreement you are not giving up any of your legal rights.

Name of Participant (please print) 
The focus group session will be audio-recorded for documentation purposes. This audio recording will be securely stored on the researcher's Ryerson University Google drive with two-factor-authentication until it has been transcribed. Once transcribed onto a word document and verified, all traces of the audio recordings will be deleted. The transcription of the audio recordings will be securely stored on the researcher's Ryerson University Google drive with two-factor-authentication.

I agree to be audio-recorded for the purposes of this study. I understand how these recordings will be stored and destroyed.

$\begin{array}{cc}\overline{\text { Signature of Participant }} & \text { Gender Fluid Discourses: } \\ & \text { How can they be incorporated into early childhood settings? }\end{array}$

NAME:

In the published document, I would like to use:

I would like to be emailed a copy of: 
Any future published materials using the data from this study

Signature of Participant

Date

\section{LIST OF SERVICES AND SUPPORTS}

4. Umbrella Mental Health Network - 691 Bloor St West, Suite 202

We offer psychology and psychotherapy services to individuals, couples, and families in the LGBTQ+ community, ranging from those queer spawn to people who identify with broader lenses of queerness

PH: 647-687-6543

EMAIL: info@umhn.ca

WEBSITE: https://www.umhn.ca

5. Dr. Nicola Brown -195 College St, $3^{\text {rd }}$ floor

If you are an individual adult looking for psychotherapy in downtown Toronto, I may be able to help. I am experienced working with: anxiety, depression, trauma, family and relationship issues, loss and grief, self-esteem and assertiveness, workplace stress, sexuality, gender identity/transition planning. My practice is gay, lesbian, bi and trans positive

WEBSITE: http://www.nicolabrown.ca/index.htm

PH: 647-501-2045

EMAIL: nicola@nicolabrown.ca

\section{Psychotherapy Referral Service}

PRS connects you with a registered psychotherapist in Toronto or the GTA. You won't have to look further to get matched up with a Toronto therapist that will use effective and professional approaches to help you. Whether you are open to getting matched to a therapist or want to select them with your preferences in mind, PRS will get you connected to a qualified therapist.

WEBSITE: https://prstoronto.com 


\section{APPENDIX F \\ Demographic Questionnaire}

\section{Gender Fluid Discourse: \\ How can it be incorporated into early childhood settings? \\ background information sheet}

INSTRUCTIONS: Please fill in this form in order to provide some basic background information about you

1. Are you an:

RECE $\square$

ECE in training

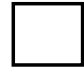

or Other:

2. Please select the kind of early learning setting you work in:

Licensed centre-based care

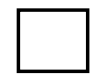

Unlicensed care

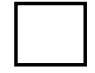

Co-operative nursery school

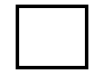

Nursery school

Early years centre

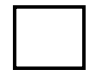

or Other:

3. Is the centre you work at:

For profit

Non profit
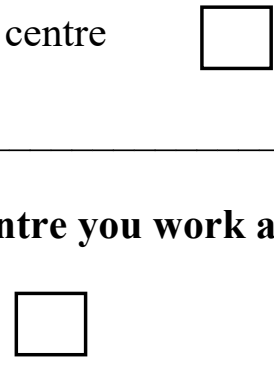

4. You have been working in the childcare field for:

$1-5$ years 
6-10 years

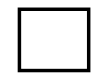

10-20 years

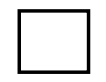

$21+$ years

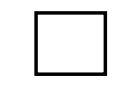

5. What is your educational background:

ECE college diploma:

BA:

MA:

$\mathrm{PhD}$ :

or Other: 


\section{APPENDIX G \\ Phone Interview Questions}

1. Can you briefly tell me a bit about yourself/ professional journey?

2. What have been your experiences with gender in early childhood settings?

3. Why is moving towards more gender fluid discourses important to you?

4. For this study, I was looking for participants who believe that the current gender discourses taking place in ECEC settings are problematic, is this something that you believe?

5. What are some things you are dissatisfied with?

6. What would you like to see changed? How can or should they be changed?

7. What are some things you would like to see happen in the field of ECEC in terms of gender fluid practice?

8. Is there something you had incorporated into your practice that worked? Or something that you wished you had?

\section{In preparation of the focus group session:}

1. What would be important for me to consider before holding this focus group?

2. In your opinion, what do you think would be important to ask my participants?

\section{Before we wrap up:}

1. Is there anything that I've missed or anything that you would like to add that I didn't touch on? 


\section{APPENDIX H \\ Focus Group Questions}

\section{Prior to main question:}

- How would you define or think about the term "gender fluidity"?

- When or what started you on this gender fluid thinking / practice journey?

- Why is gender fluid discourse important to you?

- What is important about adopting gender fluid discourses?

- Conversations about gender from this perspective are not new (academic and not) yet they do not seem to be reflected in a large majority of the field of ECEC, why do you think this is?

- Why do you think the field of ECEC seems to remain stuck in developmental understandings of gender?

- Are educators adequately supported in order to respond to children's questions, comments, etc. surrounding gender? Why or why not? How can this be improved?

Main question: How are you incorporating gender fluid discourses with children in your practice?

\section{Post main question:}

- Do you believe what you are doing (or the approach you are taking) is working? How do you know?

- Do you believe that what you are doing is something that would be helpful to children in other centres?

- Have you seen gender fluid discourses have positive effects on children's daily lives? How so?

- When you have worked to incorporate gender fluid discourses into your practice, have you ever had trouble with families or parents?

- Is a shift in thinking towards gender in the ECEC field possible? What can we do to make this possibility a reality?

- What are some things you would like to see happen in the field of ECEC in terms of gender fluid practice?

- Can academic theories be used as a tool to shift thinking in ECEC (developmental vs. ?), is this something that is possible?

- Based on what you know, believe and practice now, are there things you wish you did differently in the past? What were they? Why do you think you responded the way that you did? How would you respond now?

- Is there something you had incorporated into your practice that worked? Or something that you now wished you had? (\#8 from phone interview)

\section{Possible Probes:}

- Daily activities (play, meals, transitions, etc.)

- Children's peer relationships and interactions

- Reactions from other adults in the room, at pick up time

- Examples where a gender fluid discourse was implemented effectively, not effectively 
- Examples of the dominant discourse surrounding gender that you found problematic or bothersome

\section{Debrief}

- Highlight key points of discussion

- Answer any final questions

- Describe how results will be used

- Inform participants how results will be made available

- Thank participants for their participation 


\section{REFERENCES}

Almy, M. C., \& Genishi, C. (1979). Ways of studying children: An observation manual for early childhood teachers (Rev. ed.) Teachers College Press.

Asghar, J (2013). Critical paradigm: A preamble for novice researchers. Life Science Journal, 10, 3121-3127. Retrieved from https://www.researchgate.net/publication/260675135 _Critical_Paradigm_A_Preamble_for_Novice_Researchers

Barbour, R (2007). Generating data. Qualitative research kit: Doing focus groups (pp. 103-114). London: SAGE Publications Ltd.

Barnikis, T. (2015). Children's perceptions of their experiences in early learning environments: An exploration of power and hierarchy, Global Studies of Childhood, 5(3), 291-304. https://doi.org/10.1177/2043610615597148

Berman, R. \& Abwai, Z. (2019). Thinking and doing otherwise: Reconceptualist contributions to early childhood education and care. In S. Jagger (Ed.) Early years education and care in Canada: A historical and philosophical overview (pp. tba). Toronto: Canadian Scholars Press.

Berman, R., Daniel, B., Butler, A., Macnevin, M., \& Royer, N. (2017). Nothing, or almost nothing, to report: Early Childhood Educators and discursive constructions of colorblindness. International Critical Childhood Policy Studies, 6 (January), 52-65.

Blaise, M. (2005). A feminist poststructuralist study of children "doing" gender in an urban kindergarten classroom. Early Childhood Research Quarterly, 20(1), 85-108. https://doi.org/10.1016/j.ecresq.2005.01.002

Blaise, M. (2009). "What a girl wants, what a girl needs": Responding to sex, gender, and sexuality in the early childhood classroom. Journal of Research in Childhood 
Education, 23(4), 450-460. https://doi.org/10.1080/02568540909594673

Blaise, M. (2014). Interfering with gendered development: A timely intervention. International Journal of Early Childhood, 46(3), 317-326. doi:10.1007/s13158-014-0122-9

Bloch, M., Swadener, B., \& Canella, G (Eds.), Reconceptualizing early childhood care and education: A reader: Critical questions, new imaginaries and social activism (pp.57-66). New York, NY: Peter Lang.

Braun, V., \& Clarke, V. (2006). Using thematic analysis in psychology. Qualitative Research in Psychology, 3(2), 77-101. doi:10.1191/1478088706qp063oa

Breneselović, D. P., \& Krnjaja, Ž. (2016). Discourses on gender in early childhood education and care (ECEC) setting: Equally discriminated against. Journal of Pedagogy, 7(2), 5177. https://doi.org/10.1515/jped-2016-0011

Britzman, D. (2007). Teacher education as uneven development: Toward a psychology of uncertainty. International Journal of Leadership in Education, 10(1), 1-12. doi:10.1080/13603120600934079

Bohman, James, "Critical Theory", The Stanford Encyclopedia of Philosophy (2013), Edward N. Zalta (ed.), Retrieved from https://plato.stanford.edu/archives/fall2016/entries /criticaltheory/s.

Butler, J. (1999). Gender trouble: Feminism and the subversion of identity Routledge Byrne, D. (2017). What is phenomenological analysis?. Project Planner. doi:10.4135/9781526408570

Cahill, B., \& R. Theilheimer. 1999. “'Can Tommy and Sam get married?' Questions about gender, sexuality, and young children.” Young Children, 54 (1): 27-31.

College of Early Childhood Educators (2017). Reflective practice and self-directed learning 
[pdf]. Retrieved from https://www.college-ece.ca/en/Documents/CPL_Reflective_ Practice_Self_Directed_Learning.pdf\#search=self\%2Dreflection

Copple, C., Bredekamp, S. (Eds.) (2009). Developmentally appropriate practice in early childhood programs serving children from birth through age 8. Washington, DC: NAEYC

Developmentally Appropriate Practice. (n.d.). Retrieved from https://www.naeyc.org/resources/topics/dap

Ehrensaft, D., \& Spack, N. (2016). The gender creative child: Pathways for nurturing and supporting children who live outside gender boxes The Experiment. Retrieved from https://ebookcentral-proquest-com.ezproxy.lib.ryerson.ca/l ib/ryerson/detail.action ?docID $=4539790$

Emmel, N (2013). Purposeful sampling. Sampling and choosing cases in qualitative research: A realist approach (pp. 33-44). London: SAGE Publications Ltd. doi:10.4135/9781473913882

Farley, M. (2017). “Now I Feel 'Truly' Like Me!”: A discourse analysis of the ways 'the gaze' functions in two children's picture books featuring transgender and gender variant characters. $M R P, 1-29$.

Frey, B. (2018). The SAGE encyclopedia of educational research, measurement, and evaluation (Vols. 1-4). Thousand Oaks, CA: SAGE Publications, Inc. doi: $10.4135 / 9781506326139$

Gagliardi, L.-M. (2014). Playing with Gender: Taking up and challenging heteronormativity in an early childhood education setting. MRP, 3(2), 1-46. https://doi.org/http://dx.doi.org/110.21043/equilibrium.v3i2.1268 
Gansen, H. M. (2017). Reproducing (and Disrupting) Heteronormativity: Gendered Sexual Socialization in Preschool Classrooms. Sociology of Education, 90(3), 255-272. https://doi.org/10.1177/0038040717720981

Gunn, A. C. (2008). Heteronormativity and early childhood education: Social justice and some puzzling queries. University of Waikato, Hamilton, New Zealand. Retrieved from https://hdl.handle.net/10289/2671

Gunn, A. C. (2011). Even if you say it three ways, it still doesn't mean it's true: The pervasiveness of heteronormativity in early childhood education. Journal of Early Childhood Research, 9(3), 280-290. doi:10.1177/1476718X11398567

Gunn, A. C. (2017). A philosophical anchor for creating inclusive communities in early childhood education: Anti-bias philosophy and te Whāriki: Early childhood curriculum. Waikato Journal of Education, 9 doi:10.15663/wje.v9i0.390

Hidden Curriculum. (2015). Retrieved from https://www.edglossary.org/hidden-curriculum/ Horkheimer, M., (1982). Critical Theory, New York: Seabury Press.

Hunt, S. (2016). An Introduction to the health of two-spirit people: Historical, contemporary and emergent issues. National Collaborating Centre for Aboriginal Health, 28.

Iorio, J., Parnell, W., Quintero, E., \& Hamm, C. (2018). Early childhood teacher educator as public intellectual. In Bloch, M., Swadener, B., \& Canella, G (Eds.), Reconceptualizing early childhood care and education: A reader: Critical questions, new imaginaries and social activism (pp.299-312). New York, NY: Peter Lang.

James, A., Jenks, C., \& Prout, A. (1998). Theorizing childhood. New York: Teachers: College Press.

Jayanthi, M., \& Nelson, J. S. (2002). Developing a focus group guide. Savvy 
decision making (pp. 77-92). Thousand Oaks, CA: SAGE Publications, Inc. doi:10.4135/9781412985765

Kelly-Ware, J. (2016). 'What's he doing that for? He's a boy!': Exploring gender and sexualities in an early childhood setting. Global Studies of Childhood, 6(1), 147154. https://doi.org/10.1177/2043610615624519

Kessler, S. (2018). Reconceptualizing the early childhood curriculum: An unaddressed topic. In Bloch, M., Swadener, B., \& Canella, G (Eds.), Reconceptualizing early childhood care and education: A reader: Critical questions, new imaginaries and social activism (pp.35-43). New York, NY: Peter Lang.

Kroeger, J., Recker, A., Gunn, A. (2019). Tate and the pink coat: Exploring gender and enacting anti-bias principles. Retrieved from https://www.naeyc.org/resources/pubs/yc/ mar2019/exploring-gender-enacting-anti-bias

Kroeger, J., \& Regula, L. (2017). Queer Decisions in Early Childhood Teacher Education: Teachers as Advocates for Gender Non-conforming and Sexual Minority Young Children and Families. International Critical Childhood Policy Studies, 6(1), 106-121.

Kvale, S. (2007). Conducting an Interview. Doing interviews (pp. 52-66).

SAGE Publications, Ltd. https://doi.org/10.4135/9781849208963.n5

Leavy, P. (2017). Research Design. New York, NY: The Guilford Press.

Levin, R (2018). The Problem with pronouns [web page]. Retrieved from https://www.insidehighered.com/views/2018/09/19/why-asking-students-their-preferredpronoun-not-good-idea-opinion

Liamputtong, P. (2011). Managing and making sense of focus group data.

Focus group methodology: Principles and practice (pp. 165-181). 
London: SAGE Publications Ltd doi:10.4135/9781473957657

Lubeck, S. (1995). The politics of developmentally appropriate practice: exploring issues of culture class and curriculum. In B. Mallory and R. New (Eds.) Diversity and developmentally appropriate practices: challenges for early childhood education (pp. 1743). New York: Teachers College Press.

Lynch, M. (2015). Guys and dolls: A qualitative study of teachers' views of gendered play in kindergarten. Early Child Development and Care, 185(5), 679-693. https://doi.org/10.1080/03004430.2014.950260

Lyttleton-Smith, J. (2017). Objects of conflict: (re) configuring early childhood experiences of gender in the preschool classroom. Gender and Education, 1-18. https://doi.org/10.1080/09540253.2017.1332343

Mohamed, S. (2019). Ontario Early Childhood Educators' Understandings of Care, Carework and Care practices in Ontario ECEC Programs. MRP, 1-120

Mackenzie, S., \& Talbott, A. (2018). Gender justice/gender through the eyes of children: a Photovoice project with elementary school gender expansive and LGBTQ-parented children and their allies. Sex Education, 1-17. https://doi.org/10.1080/14681811.2018.1456915

MacNevin, M., \& Berman, R. (2017). The Black baby doll doesn't fit the disconnect between early childhood diversity policy, early childhood educator practice, and children's play. Early Child Development and Care, 187(5-6), 827-839. https://doi.org/10.1080/03004430.2016.1223065

Martin, K. A. (1998). Becoming a gendered body: Practices of preschools. American Sociological Review, 63(4), 494-511. doi:10.2307/2657264 
Native Land. (n.d.). Retrieved from https://native-land.ca

Nxumalo, F., \& Adair, J. K. (2019). Social justice and equity in Early Childhood Education. The Wiley Handbook of Early Childhood Care and Education, 661-681. https://doi.org/10.1002/9781119148104.ch29

O'Loughlin, M. (2018). Still waiting for the revolution. In Bloch, M., Swadener, B., \& Canella, G (Eds.), Reconceptualizing early childhood care and education: A reader: Critical questions, new imaginaries and social activism (pp.67-81). New York, NY: Peter Lang. Ontario government (2014) How does learning happen? [pdf]. Retrieved from http://www.edu.gov.on.ca/childcare/howlearninghappens.pdf

Pacini-Ketchabaw, V. (2006). Rethinking the history of Ontario day nurseries: Loci for intervention, regulation and administration: Part one. Child and Youth Care Forum, 35(2), 159-182. doi:10.1007/s10566-005-9006-3

Pacini-Ketchabaw, V., \& Prochner, L. W. (2013). Re-situating Canadian early childhood education Peter Lang

Pacini-Ketchabaw, V., Nxumalo, F., Kocher, L., Elliot, E., Sanchez, A. (2015). Journeys: Reconceptualizing early childhood practices through pedagogical narration. Toronto: University of Toronto Press. Chapter 3: Challenging Assumptions

Paechter, C. (2017). Young children, gender and the heterosexual matrix. Discourse: Studies in the Cultural Politics of Education, 38(2), 277-291. doi:10.1080/01596306.2015.1105785

Prioletta, J. (2018). Unequal education in preschool. Girlhood Studies, 11(2), 79-94. doi:10.3167/ghs.2018.110207

Rahilly, E. P. (2015). The gender binary meets the gender-variant child: Parents' negotiations with childhood gender variance. Gender and Society, 29(3), 338-361. 
https://doi.org/10.1177/0891243214563069

Robinson, K. H. (2013). Schooling the vulnerable child: Power/knowledge and the regulation of the adult normative citizen-subject. In Innocence, knowledge and the construction of childhood: The contradictory nature of sexuality and censorship in children's contemporary lives. Retrieved from https://ebookcentral-proquestcom.ezproxy.lib.ryerson.ca

Shutts, K., Kenward, B., Falk, H., Ivegran, A., \& Fawcett, C. (2017). Early preschool environments and gender: Effects of gender pedagogy in Sweden. Journal of Experimental Child Psychology, 162, 1-17. https://doi.org/10.1016/j.jecp.2017.04.014

Silin, J. (2018). Through a queer lens: Recuperative longings and the reconceptualizing past. In Bloch, M., Swadener, B., \& Canella, G (Eds.), Reconceptualizing early childhood care and education: A reader: Critical questions, new imaginaries and social activism (pp.57-66). New York, NY: Peter Lang.

Smith, K., \& Campbell, S. (2018). Social activism: The risky business of early childhood educators in neoliberal Australian classrooms. In Bloch, M., Swadener, B., \& Canella, G (Eds.), Reconceptualizing early childhood care and education: A reader: Critical questions, new imaginaries and social activism (pp.313-323). New York, NY: Peter Lang.

Stafford, A. N. (2016). "I feel like a girl inside": Possibilities for gender and sexual diversity in early primary school. BC Studies, (189), 9. Gale OneFile: CPI.Q (Canadian Periodicals), https://link-galegroup.com.ezproxy.lib.ryerson.ca/apps/doc/A453297272/CPI?u= rpu _main\&sid=CPI\&xid=2fd404cd. Accessed 28 July 2019.

Sullivan, A. L., \& Sullivan, A. L. (2016). Kindergartners studying trans* issues through I am 
Jazz. In sj Miller (Ed.), Teaching, Affirming, and Recognizing Trans and Gender Creative Youth: A Queer Literacy Framework (pp. 63-80). New York: Palgrave Macmillan US. https://doi.org/10.1057/978-1-137-56766-6_4

Surtees, N., \& Gunn, A. C. (2010). (Re) marking heteronormativity: Resisting practices in early childhood education contexts. Australasian Journal of Early Childhood, 35(1), 42.

Retrieved from https://search.informit.com.au/documentSummary; $\mathrm{dn}=029211$ 794356744 ;res=IELHSS

Taylor, A., \& Blaise, M. (2007). Queer theory. Journal of Experimental Psychology: General, $136(1), 23-42$.

Vintimilla, C. D. (2018). Encounters with a pedagogista. Contemporary Issues in Early Childhood, 19(1), 20-30. https://doi.org/10.1177/1463949116684886

Warin, J., \& Adriany, V. (2017). Gender flexible pedagogy in early childhood education. Journal of Gender Studies, 26(4), 375-386. https://doi.org/10.1080/09589236.2015.1105738

What Does LGBT2Q+ Mean? (n.d.). Retrieved from https://www.queerevents.ca/lgbt2q/whatdoes-lgbt2q-mean

Wingrave, M. (2018). Perceptions of gender in early years. Gender and Education, 30(5), 587606. https://doi.org/10.1080/09540253.2016.1258457 